\title{
A Patent Race in a Real Options Setting: Investment Strategy, Valuation, CAPM Beta and Return Volatility
}

\author{
Rujing Meng*
}

\begin{abstract}
This paper studies financial properties of venture-capital backed start-ups through a continuous-time real-options patent-race model. Numerical analysis shows that patent races, relative to a joint monopoly, cause over-investment, value-dissipation, a higher CAPM beta, a higher return volatility and more negative return correlation when firms intensively compete. A firm's CAPM beta is a complicated non-linear function of its position relative to its competitor. The magnitude of annualized return volatilities of startups can be in excess of $100 \%$. This high level of return volatility is attributed largely to technological risks and is consistent with empirical findings by Cochrane [2004].
\end{abstract}

\footnotetext{
* School of Business and School of Economics \& Finance, the University of Hong Kong, Pokfulam Road, HK. Email: MENG@hku.hk. I would like to give special thanks to my advisor Albert S. "Pete" Kyle for his continuous advice and insightful comments. Thanks also to Michael Bradley, Lorenzo Garlappi, Itay Goldstein, Daniel A. Graham, John Graham, Campbell R. Harvey, Tracy Lewis, Vojislav Maksimovic, Leslie M. Marx, Richmond Mathews, Hui Ou-yang, Curtis R. Taylor, Alexander Triantis, S. Viswanathan, Huseyin Yildirim, and seminar participants at Duke, the Board of Federal Reserve, FMA 2003 Annual Conference, HKU, Peking Univ., SFSU, Tulane and Tsinghua. All errors are mine.
} 


\title{
A Patent Race in a Real Options Setting: Investment Strategy, Valuation, CAPM Beta and Return Volatility
}

\begin{abstract}
This paper studies financial properties of venture-capital backed start-ups through a continuous-time real-options patent-race model. Numerical analysis shows that patent races, relative to a joint monopoly, cause over-investment, value-dissipation, a higher CAPM beta, a higher return volatility and more negative return correlation when firms intensively compete. A firm's CAPM beta is a complicated non-linear function of its position relative to its competitor. The magnitude of annualized return volatilities of startups can be in excess of $100 \%$. This high level of return volatility is mainly attributed to technological risks and is consistent with empirical findings by Cochrane [2004].
\end{abstract}

This paper develops a duopoly patent-race model by using a continuous-time real-options methodology. Through the patent-race model, we examine financial properties of start-up firms controlled by venture capitalists, like firms creating new software, or firms inventing NANOtechnology or WIFI-technology, or firms innovating new drugs. With the development of high technology, these firms become unarguably important in our new economy. The venture capital investment in United States companies reached about $\$ 120$ billion in year 2000. We know Creation, Invention, Innovation are essential for these firms to survive and become potentially cash cows. But, most of these firms are private and the relevant data are not available until recently. ${ }^{1}$ Thus, we know little about financial properties of these firms, such as what are these firms' investment strategies, how these firms are valued, and what are the characteristics of these firms' risk and return? This paper aims to answer these questions and to develop a model to serve as a benchmark or guidance for some future empirical work.

Start-ups are subject to three primary types of uncertainty during an innovation process. A new technology will not generate income until it is completed, so there is market demand 
uncertainty. A firm is uncertain about its technological ability or whether its new technology works, thus there is technological uncertainty. Intellectual property protection, like patents, is usually granted only to the first inventor. A firm has to strategically interact with its competitors, so there is competitive uncertainty. We build all the three-dimension uncertainty into this model. In this model, two start-ups, controlled by venture capitalists, compete to invent a new technology. Each firm chooses an investment rate at which it develops the new technology. The winner of the race is awarded a patent and starting from that point receives a sequence of cash flows, which are valued by the Capital Asset Pricing Model. The loser of the race receives nothing. Duopoly competition for the patent is modeled as a game in which there are three publicly observed state variables: the value of the patent and the expected cost-to-completion of each of the two firms. Each of the state variables is governed by its own source of risk. The value of the patent is the present value of the cash flows, which follows geometric Brownian motion subject to both systematic risk and idiosyncratic risk. The overall uncertainty underlying the patent value is referred to as "market demand uncertainty," which gives firms real options to wait for more information about the profitability of the patent. The position of each firm in the race is described by a state variable, called the expected "cost-to-completion," which measures the expected amount of money a firm needs to succeed in developing the new technology and winning the patent race (the follow-on capital). Each firm's expected cost-to-completion follows a diffusion process governed by its own idiosyncratic technological risk, which is a special case of the technology described by Pindyck [1993]. With a firm's own idiosyncratic technological uncertainty, a firm has an incentive to invest to resolve this uncertainty and learn more about how difficult the project is (learning-by-doing). A firm's investments can lead to technological improvements as well as technological setbacks. With its competitor's idiosyncratic technological uncertainty, a firm receives either preemptive threats to invest or incentives to withhold investments depending on this firm's position relative to its competitor in the patent race. In an environment with multiple sources of uncertainty, a firm has to strike a balance among the 
real options to wait, the incentives to invest or withhold investments, and the preemptive threats to invest.

The equilibrium concept is full information Markov Perfect equilibrium. Each firm chooses an investment rate constrained by its money "burn rate" to maximize its firm value given the other firm's investment rate. Although the model is formulated in continuous-time, we solve it by using numerical approximations. Using the lattice method, we develop a discrete-time implementation on a 201 x 61 x 61 grid with 600 monthly decisions, through which we examine investment strategy, valuation, CAPM beta, return volatility and return correlation of firms evolved in a patent race. ${ }^{2}$ We report the results for various relative positions of the firms throughout the race.

For comparison purpose, we use as a benchmark the case of a joint monopoly in which the two firms implement a collusive outcome. ${ }^{3}$ Comparison of financial properties between a hypothetical portfolio comprising the two competing firms and the joint monopoly shows that patent races, relative to the joint monopoly, cause over-investment, value-dissipation, a higher CAPM beta, a higher return volatility and more negative return correlation between the competing firms when the firms intensively compete. In terms of each individual firm evolved in the patent race, as intuition suggests, each firm invests more aggressively. Each firm's value is non-increasing with its own expected cost-to-completion and non-decreasing with its competitor's expected cost-to-completion. The value of each firm changes dramatically in response to moderate changes in either firm's position in the race. Each firm's CAPM beta is a complicated non-linear function of its position relative to its competitor. When a firm is close to victory, its beta is close to the underlying patent beta, but it is always greater than the patent beta reflecting the real-options value. As a firm drops back further away from victory but is still investing, its percentage exposure to patent-value-risk increases. As a firm continues dropping back and finally stops investing, its value becomes less sensitive to the patent value and more sensitive to its competitor's technological risk which is idiosyncratic. Another interesting result 
is that the magnitude of the annualized return volatility of a start-up can be in excess of $100 \%$. This level is quite high comparing to the empirical evidence that typical values of the volatility of a stock are in the range of $20 \%$ to $40 \%$ per annum. ${ }^{4}$ This high level of return volatility for a venture-capital backed start-up is largely attributed to technological risks and is consistent with recent empirical findings documented by Cochrane [2004]. Cochrane [2004] studies the risk and return of venture capital and finds that the arithmetic returns of venture capital, even after correction of selection bias, are very volatile, and the annualized standard deviation is about 100\%. The model also shows that each firm's return volatility can be decomposed into systematic market demand risk and the two firms' idiosyncratic technological risks. The proportion of each component changes with a firm's position in the patent race. When a firm is close to victory, its return volatility is mainly caused by market demand risk. When a firm is close to the other firm in the race, the two firms' idiosyncratic technological risks account for the majority of its return volatility. When a firm is far behind and stops investing, the firm essentially stays away from competition unless the other firm experiences setbacks. The firm's return volatility is mainly caused by its competitor's idiosyncratic technological risk in this situation. When both firms invest and intensively compete, beta and return volatility of a firm increase when this firm suffers setbacks or its competitor makes improvements. Regarding return correlation of the two competing firms, the model implies that the two firms' returns are perfectly correlated by the common factor of patent value when neither firm invests and most negatively correlated when both invest. This implication is confirmed by our numerical analysis. These results implies that a venture capitalist should encourage its portfolio firms to cooperate more and include competing firms into its portfolio if the venture capitalist has spent hands-on effort in any of these competing firms.

In addition, we conduct a comparative-static analysis of parameters of market demand volatility, dividend yield, and technological volatility to study how the leader and the follower react differently to these key underlying parameters. The analysis implies that a firm's position in 
the patent race relative to that of its competitor is an important control variable when we study investment behavior and other financial properties of firms involved in a patent race. This control variable has been ignored in empirical studies. We provide a discussion of empirical proxy for this control variable.

We believe that the above results would be difficult to capture in a simple two- or threeperiod model, and thus justify the use of numerical approximations to a dynamic game in continuous-time.

\section{Literature Review}

This research is related to several strands of literature. One is that of the patent race in economics. Technological competition has been investigated first through stationary games under uncertainty by Loury [1979], Dasgupta and Stiglitz [1980] and Lee and Wilde [1980], and then through dynamic games under uncertainty but without explicit strategic interactions pioneered by Reinganum [1981, 1982], or through dynamic games with strategic interactions but without uncertainty pioneered by Fudenberg et al. [1983] and Harris and Vickers [1985]. Finally, strategic interactions and technological uncertainty are combined within a dynamic structure, as in Judd [1985], Grossman and Shapiro [1987], and Harris and Vickers [1987]. Models in this line of research all lack market demand uncertainty because the patent value is set as a constant. A real-options methodology has not been applied. Therefore, the value of the option to delay investments embedded in market demand uncertainty has been ignored. As a result, the investment strategies derived in those papers lack the “delay” feature.

The second stream of the literature is investment under uncertainty using standard real-

options techniques. ${ }^{5}$ The papers along this line, represented by the work of McDonald and Siegel [1986], Pindyck [1988], and Dixit [1989], highlight market demand uncertainty. Therefore, the real-options premium of delaying investments, which has been ignored in the literature on the patent race, is the main finding of this category of research. But those papers have typically 
ignored strategic interactions between firms. They regard firms as either monopolists or entities in a perfectly competitive market. ${ }^{6}$

This paper unifies the above two lines of research combining real-options with strategic interactions. Therefore, this paper is also related to a recently growing literature of option exercise games represented by the work of Kulatilaka and Perotti [1998], Grenadier [2003] and Weeds [2002]. ${ }^{7}$ Most existing models assume risk-neutrality precluding the analysis of CAPM beta and return volatility of firms evolved in competition. Technological uncertainty has also often been ignored. Childs and Triantis [1999] examine dynamic R\&D investment policy and valuation for a firm with multiple $R \& D$ projects, which can run in parallel or in sequential. They provide a thorough analysis of the interactions across projects. In our model, both firms are assumed to have a single project. Novy-Marx [2003] investigates the optimal investment decisions of heterogeneous firms in a competitive, uncertainty environment and shows that the strategic equilibrium real-options premia are significant. Grenadier [1999] and Lambrecht and Perraudin [1999] study option exercise games under incomplete information. In our model, both firms always have complete information.

Our continuous-time model is also related to parallel works by Miltersen and Schwartz [2004] and Garlappi [2004]. Miltersen and Schwartz [2004] provide a welfare analysis of R\&D spending with competitive effects in an environment with multiple sources of uncertainty. They adapt a more general version of the technology described by Pindyck [1993], including both technical shocks and input shocks. They solve the model with a variation of the LongstaffSchwartz method (Longstaff and Schwartz [2001]) and illustrate an example in which firms start with a particular position of head-to-head. In our model, we apply the "brute force" lattice method and provide the results for various relative positions of the firms throughout the race. It allows us to analyze the different behavior and financial properties the leader and the follower may have. Garlappi [2004] studies the dynamics of firms' risk premia in a duopoly patent race with the same three sources of uncertainty as in this paper. He provides analytical solutions to a 
two-stage game and numerical analysis to a more general five-stage game. His model is different from this model in that his technology is more discrete and does not allow technological setbacks. Instead, firms jump over a series of hurdles before winning the patent race. By introducing technological setbacks and allowing a firm to be far away from its competitor, we find that startups' CAPM beta is a non-linear function of its position in the race. A firm's beta can become pretty tiny when the firm is far behind of its competitor. In addition, the hazard rate is independent of a firm's investments in his model. Kyle and Meng [2004] extend this model by allowing firms to have different research bandwidths and by allowing strategic investments and acquisitions to occur, subject to transactions costs. All of the papers use a real-options approach to model competition.

The paper is organized as follows. Section I describes the model set-up. Section II describes the numerical implementation. Section III discusses the equilibrium investment strategy, valuation, CAPM beta, return volatility and return correlation of firms involved in the patent race. Section IV provides a comparative-static analysis on parameters of market demand volatility, dividend yield of the patent value and technological volatility. Section V concludes with a discussion of further research.

\section{THE MODEL}

There are two all equity-financed firms, indexed by A and B, pursuing a single project. ${ }^{8}$ At time $t=0$, the two firms enter a race against each other to complete an invention. The first firm to complete an invention (hereafter, the winner of the patent race) will be awarded a patent. During the course of the patent race, each firm makes continuous-time sequential investment decisions until the winner emerges. Duopoly competition for the patent is modeled as a game in which there are three publicly observed state variables: the value of the patent, and the expected cost-to-completion of each of the two firms. These state variables are described as follows. 


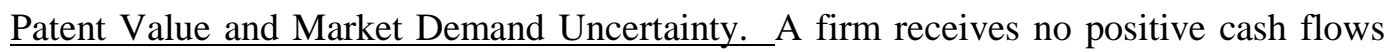
unless it is the winner of the patent race, i.e., the first to complete the project and receive a patent. If the winning firm obtains the patent at time $t$, it immediately begins to receive an infinitelylived stochastic stream of cash flows, denoted $D(t)$, which is valued by the Capital Asset Pricing Model (CAPM). The value of the winning firm is the value of this stream of cash flows. The losing firm receives nothing and becomes worthless. The stochastic process $D(t)$ is assumed to follow geometric Brownian motion. Let $\mu$ denote the drift, let $\beta$ denote the CAPM beta, let $\sigma_{m}$ denote the market volatility, let $\sigma_{I}$ denote idiosyncratic volatility, and let $\sigma$ denote dividend volatility. Then we can write

$$
\frac{d D}{D}=\mu d t+\beta \sigma_{m} d z_{m}+\sigma_{I} d z_{x}=\mu d t+\sigma d w
$$

Here, dividend volatility, $\sigma=\sqrt{\beta^{2} \sigma_{m}^{2}+\sigma_{I}^{2}}$, is referred to as "market demand uncertainty." It contains both systematic and idiosyncratic components. Let $\lambda_{m}$ denote the risk premium on the market portfolio, let $r_{f}$ denote the risk-free rate, and let $P_{m}(t)$ denote the value of a share in the market portfolio with dividends reinvested. Then we can write

$$
\frac{d P_{m}}{P_{m}}=\left(r_{f}+\lambda_{m}\right) d t+\sigma_{m} d z_{m}
$$

Using Gordon's growth formula, the present value of the stream of the patent cash flows, denoted $x(t)$, is given by $x(t)=\frac{D(t)}{r_{f}+\beta \lambda_{m}-\mu}$. The "patent value" $x(t)$ is one of the state variables affecting the value of both firms. The patent value $x(t)$ follows the process

$$
\frac{d x}{x}=\mu d t+\beta \sigma_{m} d z_{m}+\sigma_{I} d z_{x}=\mu d t+\sigma d w
$$

Let $\delta$ denote the “dividend yield,” the denominator in Gordon's Growth Formula given by 


$$
\frac{D(t)}{x(t)}=r_{f}+\beta \lambda_{m}-\mu
$$

Intuitively, the dividend yield $\delta$ represents the rate at which the present value of the patent decays through time as a result of no patent being granted; it represents the opportunity cost of delaying winning the patent. Intuitively, if the dividend yield $\delta$ is smaller (holding the patent value $x(t)$ constant), then the "option to delay" is more valuable and firms will have an incentive to pursue the patent less aggressively. We assume $\delta>0$ to eliminate the scenario whereby firms wait forever for a more favorable patent value. Because the patent value $x$ indicates the overall economic condition of the industry, we refer to the time when $x$ is at high levels as a "bull market" and the time when $x$ is at low levels as a "bear market."

Investment Rates and Technological Uncertainty. The state of the patent race is described by two state variables, $k^{A}(t)$ and $k^{B}(t)$, denoting the two firms' expected "cost-tocompletion," respectively. We assume both $k^{A}(t)>0$ and $k^{B}(t)>0$ at the beginning of the race. Let $I^{A}(t)$ and $I^{B}(t)$ denote the two firms' investment rates, respectively. A positive investment rate $I^{A}(t)$ tends to reduce $k^{A}(t)$, and similarly a positive investment rate $I^{B}(t)$ tends to reduce $k^{B}(t)$. A firm wins the patent race when its cost-to-completion falls to zero before the other firm does.

A special case of the random technology described by Pindyck's [1993] is used. ${ }^{9}$ Expected cost-to-completion $k^{A}(t)$ and $k^{B}(t)$ are assumed to follow a diffusion process of the following form, where $\theta^{A}$ and $\theta^{B}$ are cost technological volatility parameters, which are referred to "idiosyncratic technological uncertainty” of firm A and firm B, respectively:

$$
d k^{A}=-I^{A} d t+\theta^{A}\left(I^{A} k^{A}\right)^{1 / 2} d z^{A}
$$




$$
d k^{B}=-I^{B} d t+\theta^{B}\left(I^{B} k^{B}\right)^{1 / 2} d z^{B}
$$

Here, $d z^{A}$ and $d z^{B}$ denote idiosyncratic white noise processes, also distributed independently from the financial risks $d z_{m}$ and $d z_{x}$. Our CAPM assumption implies that any risk associated with the expected cost-to-completion is diversifiable, i.e., it is priced in a risk neutral manner. This specification has several attractive features. First, the drift terms $-I^{A} d t$ and $-I^{B} d t$ indicate that a dollar of investment reduces expected cost-to-completion by a dollar. Second, the diffusion terms $\theta^{A}\left(I^{A} k^{A}\right)^{1 / 2} d z^{A}$ and $\theta^{B}\left(I^{B} k^{B}\right)^{1 / 2} d z^{B}$ indicate that expected cost-tocompletion changes randomly, with many small unexpected improvements (reductions in $k^{A}(t)$ and $k^{B}(t)$ ) as well as many small unexpected setbacks (increases in $k^{A}(t)$ and $k^{B}(t)$ ). Technological setbacks mean that a firm realizes that more money must be spent or more time is needed to pursue the project than was previously believed. ${ }^{10}$ Third, there is a "learning by doing" feature: a firm's expected cost-to-completion does not change if the firm does not invest, i.e., $d k^{A}=0$ if $I^{A}=0$ and $d k^{B}=0$ if $I^{B}=0$. Investing not only tends to push the firms towards victory by reducing expected cost-to-completion but also tends to reduce uncertainty about how much investment will eventually be required to drive $k^{A}(t)$ or $k^{B}(t)$ to zero. Let $I_{\max }^{A}$ and $I_{\max }^{B}$ denote fixed maximum investment rates of firm A and firm B, respectively, reflecting their research bandwidths. We assume firms have the same magnitude of research bandwidth, i.e., $I_{\max }^{A}=I_{\max }^{B}=I_{\max } \cdot{ }^{11}$ Firm A and firm B choose $I^{A}(t)$ and $I^{B}(t)$ from the closed interval $\left[0, I_{\max }\right]$. As we shall see later, the square root applied to $I^{A}(t)$ and $I^{B}(t)$ in the diffusion terms together with the assumption that there are no adjustment costs on capital will lead to "bang-bang” solutions in which a firm invests at the maximum rate or not at all. Thus, both 
firms face essentially a binary choice between investing at its maximum rate $I_{\max }$ or not investing at all.

As the race unfolds, a firm could become the follower, whose cost-to-completion is higher than that of the other firm $\left(k^{i}>k^{j} ; i=A, B ; j=B, A\right)$, or the leader, whose cost-tocompletion is lower than that of the other firm $\left(k^{i}<k^{j} ; i=A, B ; j=B, A\right)$. The firms could also tie in the race $\left(k^{A}=k^{B}\right)$, which is referred to as "head-to-head."

Firm Value. There are three state variables which describe the state of competition between the two firms: the patent value $x(t)$, the expected cost-to-completion of firm A $k^{A}(t)$, and the expected cost-to-completion of firm B $k^{B}(t)$. We assume that both firms observe all the three state variables at all times. Firm value of each firm is a function of the three state variables. Let $F^{A}\left(x, k^{A}, k^{B}\right)$ and $F^{B}\left(x, k^{A}, k^{B}\right)$ denote the firm value of firm $\mathrm{A}$ and firm $\mathrm{B}$, respectively.

Equilibrium. We employ the solution concept of Markov Perfect Equilibrium (see Maskin and Tirole [1988]). ${ }^{12}$ For a given date $t$ and for every state $\left(x, k^{A}, k^{B}\right)$ there is a subgame starting from that state. At each subgame, the information set of either firm is a set of realizations of the state variables $x, k^{A}$, and $k^{B}$ at time t. There are countless paths leading to this set of realizations. However, this set of realizations is the only payoff-relevant information at time $t$. The action set available to each firm includes any investment rate level in the range of $\left[0, I_{\max }\right]$. In equilibrium, a Markov equilibrium strategy maps the information set to the action set for each firm.

A firm's investment decision is a function of the three state variables: $I^{A}\left(x, k^{A}, k^{B}\right)$ and $I^{B}\left(x, k^{A}, k^{B}\right)$. At subgame $\left(x, k^{A}, k^{B}\right)$, let the investment strategy profile $\left\{I^{\text {Aopt }}\left(x, k^{A}, k^{B}\right), I^{\text {Bopt }}\left(x, k^{A}, k^{B}\right)\right\}$ construct a Nash Equilibrium such that a firm maximizes its 
firm value by optimally choosing an investment rate given the other firm's optimal investment strategy. Since the mathematical derivation is symmetric for the two firms, we only show the derivation of firm A's strategy. Given firm B's optimal investment strategy $I^{\text {Bopt }}\left(x, k^{A}, k^{B}\right)$ at subgame $\left(x, k^{A}, k^{B}\right), I^{A}\left(x, k^{A}, k^{B}\right)=I^{\text {Aopt }}\left(x, k^{A}, k^{B}\right)$ solves firm A's value function:

$$
\begin{aligned}
& F^{A}\left(x, k^{A}, k^{B}\right)=\underset{I^{A} \in\left[0, I_{\max }\right]}{\operatorname{Max}}\left\{-I^{A} d t+E^{*}\left\{e^{-r d t} F^{A}\left(x+d x, k^{A}+d k^{A}, k^{B}+d k^{B}\right)\right\}\right\} \\
& \text { s.t. }\left\{\begin{array}{l}
d x=\mu^{*} x d t+\sigma x d w \\
d k^{A}=-I^{A} d t+\theta^{A}\left(I^{A} k^{A}\right)^{1 / 2} d z^{A} \quad, \forall t \\
d k^{B}=-I^{B o p t} d t+\theta^{B}\left(I^{B o p t} k^{B}\right)^{1 / 2} d z^{B}
\end{array}\right.
\end{aligned}
$$

The expectation operator notation $E^{*}\{\ldots\}$ refers to the expectation with respect to the risk-neutral probabilities. The risk neutral probabilities are obtained by changing $\mu$ to $\mu^{*}=\mu-\beta \lambda_{m}$, i.e. by deflating the true growth rate on the patent's cash flows by the risk premium on the patent's cash flows, so that Gordon's growth formula gives the same value for winning the patent in a risk neutral model as in the CAPM model, i.e.

$$
x(t)=D(t) /\left(r_{f}+\beta \lambda_{m}-\mu\right)=D(t) /\left(r_{f}-\mu^{*}\right)
$$

Note that the dividend yield $\delta$ remains the same and is given by

$$
\delta=r_{f}+\beta \lambda_{m}-\mu=r_{f}-\mu^{*}
$$

The intuition behind this result is that the investors can hedge out market risk associated with investments in the two firms by trading the market portfolio; this leaves them with idiosyncratic risk, with respect to which they are risk neutral. Therefore, the value of the firm can be evaluated without knowing investors' risk preference or the true growth rate $\mu$ on the patent's cash flows. A proof of this point is provided in appendix 1.

Note that the equations state that the value of a firm is the present value of its riskadjusted cash flows, discounted at the risk-free rate. The positive cash flows are the cash flows 
on the patent, received if and when the firm wins. If a firm loses the race, the firm receives zero. The negative cash flows are the cost-to-completion, which we can think of as new equity being injected into the firms. Because the model fits specifically venture-capital backed growth firms, we can interpret a firm's expected cost-to-completion $k^{i}$ as the expected amount of "follow-on" capital that firm i needs to be successful. The maximum investment rate $I_{\max }$ can be interpreted as the maximum "burn rate.” As the race goes on, a firm's value may increase because the new capital invested in the firm allows it to improve its chances of winning the patent race. Even under the risk-neutral probabilities, the value of a firm increases faster than the risk-free rate because new capital (like negative dividends) is being injected into the firm when it invests.

In the continuous-time framework, the Bellman Equation of firm A given firm B's optimal investment strategy $I^{\text {Bopt }}$ is

$\underset{I^{A} \in\left[0, I_{\text {max }}\right.}{\operatorname{Max}}\left\{\left(\frac{1}{2} \sigma^{2} x^{2} F_{x x}^{A}+\left(r_{f}-\delta\right) x F_{x}^{A}\right)+I^{A}\left(\frac{1}{2}\left(\theta^{A}\right)^{2} k^{A} F_{k^{A} k^{A}}^{A}-F_{k^{A}}^{A}-1\right)+I^{B p p t}\left(\frac{1}{2}\left(\theta^{B}\right)^{2} k^{B} F_{k^{B} k^{B}}^{A}-F_{k^{B}}^{A}\right)+\left(-r_{f} F^{A}\right)\right\}=0$ (10).

The Bellman Equation is nicely grouped with brackets into four parts as shown above. The first part corresponds to market demand uncertainty, the second part corresponds to firm A's own technological uncertainty, and the third part corresponds to the competitor firm B's technological uncertainty, representing competitive uncertainty. Even though the two firms' technological uncertainties are independent, each firm must consider its competitor's technological uncertainty. The final part represents opportunity costs.

Because of the square root term in the processes of the cost-to-completion and the assumption of no adjustment costs on capital, the Bellman Equation is linear in each firm's investment strategies $I^{A}$ and $I^{B}$. The linearity of the Bellman equation implies that in the continuous-time limit, the investment strategy of firm A depends on the coefficient of $I^{A}$ in the Bellman equation of firm A, and the investment strategy of firm B depends on the coefficient of $I^{B}$ in the Bellman equation of firm B. If the coefficient is positive, the firm has a dominant 
strategy to invest at the maximum rate $I_{\max }$. If the coefficient is negative, the firm has a dominant strategy to choose a zero investment rate. If the coefficient is zero, the firm is indifferent as to its investment rate. In the continuous-time limit, a zero coefficient is a zero probability event. Hence, the action set available to a firm becomes binary: $\{$ Invest, Mothball $\}$. We also assume that the firms make a binary choice in the numerical implementation.

In the numerical implementation, if the firms have dominant strategies, then each firm plays its dominant strategy. ${ }^{13}$ Otherwise, there may be multiple solutions and the solutions may involve mixed strategies. When there are multiple equilibria in which only one firm invests and the firms are indifferent as to who invests, we assume that the firm with larger value from investing makes the investment. When there are multiple equilibria in which the firms are indifferent between both invest and both mothball, we assume that both firms invest. Our results remain robust when these assumptions are relaxed. When equilibrium involves mixed strategies, we assume that firms play mixed strategies although this is not reflected in the above notation.

Except for the small region of mixed strategies, the strategies of the firms can be described by four sets of points, i.e., both firms invest, only firm A invests, only firm B invests, and neither firm invests.

To complete a description of the equilibrium, it is also necessary to discuss the joint monopoly scenario in which two firms become separate divisions of a joint monopoly but the research bandwidths of the two firms remain uncombined. Let $F^{J M}\left(x, k^{A}, k^{B}\right)$ denote the value of the joint monopoly, the Bellman equation now has the joint monopoly maximizing value by choosing both investment rates:

$\underset{\left.I^{A} \in\left[, r_{\text {nax }}\right]\right]^{M} \in\left[0, r_{\text {nax }}^{B}\right.}{M b x}\left\{\left(\frac{1}{2} \sigma^{2} x^{2} F_{x x}^{M}+\left(r_{f}-\delta\right) x F_{x}^{M}\right)+I^{A}\left(\frac{1}{2}\left(\theta^{A}\right)^{2} k^{A} F_{k^{A} k^{A}}^{M}-F_{k^{A}}^{M}-1\right)+I^{B}\left(\frac{1}{2}\left(\theta^{B}\right)^{2} k^{B} F_{k^{B} k^{B}}^{M}-F_{k^{B}}^{M}-1\right)+\left(-r_{f} F^{M}\right)\right\}=0$. (11).

The Bellman equation of the joint monopoly remains linear in both $I^{A}$ and $I^{B}$. This paper does not consider the scenario in which one firm submits a bid for the other firm to achieve any degree 
of collusive outcome. Kyle and Meng [2003] extend this paper to allow strategic investments and acquisitions to be endogenous equilibrium outcomes.

For comparison purposes, we also construct a hypothetical portfolio comprising

competing firms $\mathrm{A}$ and $\mathrm{B}$. Let $F^{P}\left(x, k^{A}, k^{B}\right)$ denote the value of the portfolio, then we have $F^{P}\left(x, k^{A}, k^{B}\right)=F^{A}\left(x, k^{A}, k^{B}\right)+F^{B}\left(x, k^{A}, k^{B}\right)$. We will compare this hypothetical portfolio with the joint monopoly in terms of investment strategy, valuation, CAPM beta and annualized return volatility.

\section{NUMERICAL IMPLEMENTATION}

Since an effort to obtain a closed-form solution for this game is likely futile, we have solved the model numerically by using both the explicit finite difference method and the "brute force” lattice method. The properties of the model are robust to both methods. Here we only provide a detailed discussion of the lattice method and related properties.

Assumptions. The assumed values of the exogenous parameters in the base model are as follows: $\delta=3 \%, \quad r_{f}=5 \%, \beta=1.00, \sigma_{m}=20 \%, \quad \sigma=30 \%, \quad \theta^{A}=\theta^{B}=0.60, \quad I_{\max }=10$ These values imply $\mu^{*}=r_{f}-\delta=2 \%, \sigma_{I}=\left(\sigma^{2}-\beta^{2} \sigma_{m}^{2}\right)^{1 / 2}$. Time is discretized, with decisions made at $\mathrm{N}+1$ dates $0=t_{0}, t_{1}, \ldots, t_{N}=\mathrm{T}$, so that $\Delta t=t_{n+1}-t_{n}=$ one month. The horizon $\mathrm{T}$ is chosen as 50 years. Thus, we have $\mathrm{N}=600$. It is worth noting that the results are robust under a wide spectrum of parameter values.

For the purpose of numerical implementation, we also discretize the space of the three state variables. Instead of discretizing three diffusion state variables themselves, we discretize three transformed variables: $\ln (x(t)),\left(k^{A}(t)\right)^{1 / 2}$, and $\left(k^{B}(t)\right)^{1 / 2}$. Note that the dynamics of the transformed variables are given from Ito’s lemma by 


$$
\begin{gathered}
d(\ln (x))=\left(r_{f}-\delta-\frac{1}{2} \sigma^{2}\right) d t+\sigma d z, \\
d\left(\left(k^{A}\right)^{1 / 2}\right)=-\frac{1}{2} I^{A}\left(1+\frac{1}{4}\left(\theta^{A}\right)^{2}\right)\left(k^{A}\right)^{-\frac{1}{2}} d t+\frac{1}{2} \theta^{A}\left(I^{A}\right)^{\frac{1}{2}} d z^{A}, \\
d\left(\left(k^{B}\right)^{1 / 2}\right)=-\frac{1}{2} I^{B}\left(1+\frac{1}{4}\left(\theta^{B}\right)^{2}\right)\left(k^{B}\right)^{-\frac{1}{2}} d t+\frac{1}{2} \theta^{B}\left(I^{B}\right)^{\frac{1}{2}} d z^{B} .
\end{gathered}
$$

The chosen transformations have the property that the instantaneous variance in the transformed variables is constant. For the value of the patent $x(t)$, we choose 201 points, equally spaced in the transformed variable $\ln (x)$, such that the smallest point corresponds to $x=1$ and the largest point corresponds to $x=10,000$. For each of the expected cost-to-completion variables $k^{A}$ and $k^{B}$, we choose 61 points, equally spaced in the transformed variables $\left(k^{A}\right)^{1 / 2}$ and $\left(k^{B}\right)^{1 / 2}$, such that the smallest value corresponds to $k^{A}=k^{B}=0$ and the largest value corresponds to $k^{A}=k^{B}=225$.

The game is solved by using the "brute force" lattice method of backward induction from the terminal date $t_{N}=50$ years , corresponding to $\mathrm{N}=600$. We use an Euler approximation for all three transformed state variables. We approximate the normally distributed transition probabilities in the Euler approximation by mapping the true outcome to the closest transformed outcome in the space of transformed state variables within two standard deviations (rounded up) of the expected outcome. When a cost-to-completion variable hits its minimum value, we assume that the respective firm wins the patent at that point. If both firms win the patent at the same time, we split the patent value equally between the two firms. When the state variables otherwise hit their maximum or minimum values, we do not assume that they are absorbed; random fluctuations are allowed to push them back into the interior of the space of state variables at a later date. Note that our numerical implementation allows the state to jump more than one grid point from one month to the next. A typical large jump is two or three grid points. In the 
continuous-time model, by contrast, a firm cannot move from one state to another discontinuously; it must pass through intervening states. ${ }^{14}$

Since the strategy space is three dimensional, for the purpose of describing the equilibrium, we choose a patent value of $x=100$ (e.g. \$100 million), the midpoint of the grid of

the transformed variable $\ln (x)$, then discuss the results for various values of the firms' costs-tocompletion in the next section.

Note that the expected cost-to-completion variables $k^{A}$ and $k^{B}$ have not been discounted to obtain their present values. The value of the patent, $x$, is the present value of the cash flows generated by the patent if a firm wins immediately. If a firms wins at some point in the future, the present value of the patent is reduced by the foregone dividends, which accrue at rate $\delta$.

\section{FINANCIAL PROPERTIES OF EQUILBRIUM}

This section examines some financial properties of the equilibrium revealed in the numerical example. We provide the results for the joint monopoly, firm $\mathrm{A}$ in the patent race, and the portfolio comprising firms A and B in the race. We also provide comparison between the portfolio and the joint monopoly. In each subsection below, we first provide a summary of the results, and then discuss the results in detail by illustrating graphs of the numerical example.

\section{A. Over-Investment and Rent Dissipation.}

Summary of the results in this sub-section:

1). Competition makes firms eager to invest and as a result they over-invest relative to the joint monopoly scenario.

2). Over-investment induced by competition erodes the aggregate value of the firms relative to the joint monopoly scenario. 
Properties of Investment Strategies of Joint Monopoly. To further understand the duopoly competitive equilibrium, we use the scenario of joint monopoly as a useful benchmark. Joint monopoly by definition implements a collusive outcome, which maximizes the joint profits of the two firms, given that the two firms maintain separate research bandwidths. The investment behaviors of the two firms are illustrated in Figure 1, where the value of the patent is fixed at $x=$ 100 , the horizontal axis is the expected cost-to-completion of firm A $k^{A}$ and the vertical axis is the expected cost-to-completion of firm $\mathrm{B} k^{B}$. In this figure, the light gray (orange) area is where firm A invests and firm B does not; the dark (blue) area is where firm B invests and firm A does not; and the un-shaded white area is where neither firm invests. The key properties to note in this figure are the following:

1. The point where each firm's expected cost-to-completion is equal to the value of the patent is well inside the area where neither firm invests. The real option value of waiting induces the joint monopolist to delay investment when a naïve NPV rule would suggest that the project has a positive NPV.

2. One of the two firms will invest if either of the two firms has an expected cost-tocompletion less than 36. In this case, the firm which invests is typically the firm with the lower expected cost-to-completion. This can be seen in Figure 1, where the investment area of firm A corresponds to an area above the 45-degree line, and the investment area of firm B is below the 45-degree line.

3. Although it is theoretically possible that under joint monopoly both firms invest at the same time, this does not happen in this example. The rent dissipation that results from two firms investing simultaneously is always greater than the benefit of earlier completion of the project. However, two firms in a joint monopoly can invest simultaneously if the patent value is set at a much higher level than that used in this example. In that case, both firms invest along the 45degree line not far from the origin. Moreover, if the dividend yield is much higher than $3 \%$ that 
was used in this example, the joint monopoly is eager to generate cash flows from the patent at the earliest possible time. As a result, if the patent value is large enough, both firms in the joint monopoly will invest simultaneously.

Properties of Investment Strategies of Duopoly Competition. Figures 2 and 3 illustrate equilibrium investment strategies for firm A and the hypothetical portfolio comprising competing firms A and B in the duopoly patent race. The layout for these figures is the same as in Figure 1, with the patent value fixed at 100, firm A's cost-to-completion plotted on the horizontal axis and firm B's cost-to-completion plotted on the vertical axis. In Figure 2, the light gray (yellow) region is where firm A invests and the un-shaded white region is where firm A mothballs. Duopoly competition prompts firm A to be more aggressive in making investments than it is in the case of joint monopoly, which is evident if one compares Figure 2 with Figure 1. Investment strategies of both firms A and B are plotted in Figure 3. As in Figure 1, the light gray (yellow) area is where firm A invests but firm B does not, and the dark (blue) area is where firm B invests but firm A does not. The medium gray (green) area is where both firms invest. The 45-degree line, also called the "equal-cost-to-completion line,” is where firms are head-to-head. Important properties of this graph are the following:

1. There is an extensive area where both firms invest "inefficiently" in comparison with the joint monopoly case. When two firms are close in the competition, they both invest around the equal-cost-to-completion line (45-degree line). In the northwest or southeast regions where one firm is way ahead in the competition, both firms invest according to the joint monopoly investment rule.

2. The northeast boundary of the medium gray (green) area where both firms invest reaches the point where each firm's expected cost-to-completion is approximately equal to the value of the patent. Competition dissipates the real option value of waiting as will be discussed in detailed when we discuss properties of firm value. 
3. Figure 4 shows the effect of an increase in the patent value from 100 to 151 on the firms' investment strategies. It has the same scale and color scheme as Figure 3. The main difference is that investment regions are larger due to an increased profitability of the patent. This implies that a firm is more likely to invest during a bull market when the size of the market $x$ is high. ${ }^{15}$ Intuitively, the investment regions shift outward along rays from the origin. This intuition makes it possible to describe the dynamics of the patent race. When firm A invests, resolution of uncertainty results in movements toward east and west, but not north and south. Success of firm A pushes points west, and firm A wins when points hit the vertical axis. When firm B invests, resolution of uncertainty results in movements toward north and south, but not in movements toward east and west. Success of firm B pushes points on the graph south, and firm B wins the patent when points hit the horizontal axis. Since increases in patent values shift the entire investment region along a ray away from the origin, we can also think of the shift as having a similar relative effect as staying on the same Figure but shifting the point towards the origin. In other words, from a graphical perspective, an increase in patent value is like a reduction in both firms' cost-to-completion with a change in scale. Using this intuition, we can think of an increase in patent value as a shift of points along a ray towards the origin and a decrease in patent value as a shift of points along a ray away from the origin.

Properties of Firm Value of Joint Monopoly. Figure 5 plots iso-value lines for the joint monopoly. The layout for this figure is the same as in Figures 1-3, with the patent value fixed at 100, firm A's cost-to-completion plotted on the horizontal axis and firm B's cost-to-completion plotted on the vertical axis. The dotted-curves are the contour plot of the joint monopoly's investment regions. The intervals between the iso-value lines are 2. The iso-value lines for the joint monopoly's value have the same shape as the Leontief technology with a kink on the 45degree line. As one of the properties of the Leontief technology, the value of the joint monopoly is determined by the efficient firm whose cost-to-completion is lower. As shown in the graph, the value of the joint monopoly is increasing as firm A's cost-to-completion decreases in the area 
above the 45-degree line where firm A invests, or increasing as firm B's cost-to-completion decreases in the area below the 45-degree line where firm B invests. As the size of the market increases and thus points shift along a ray towards the origin using the change of scale intuition, the value of the joint monopoly increases.

Properties of Firm Value of Duopoly Competition. Equilibrium firm value for firm A and the hypothetical portfolio comprising firms A and B in the duopoly patent race are illustrated in Figures 6 and 7, respectively. The layout for these figures is the same as in Figure 5. The dotted-curves are the contour plot of both firms' investment regions. As shown in Figure 6, firm A's value is non-increasing in its own cost-to-completion and non-decreasing in the other firm's cost-to-completion. The intervals between the iso-value lines represent factors of two in value. Figure 6 shows that dramatic changes in firm A's value occur in response to seemingly modest changes in firm A’s costs-to-completion. Firm A’s value drops quickly after firm A lags behind in the competition (below 45-degree line), especially after firm A stops investing (below the lower dotted-curve). When firm A just stops investing (just away from the lower dotted-curve), its value decreases from 2 million to 1 million. As shown in Figure 7, the sum of the firm values of competing firms A and B is also symmetric along the 45-degree line with a kink on the 45degree line as the firm value of the joint monopoly. However, the kinks are more tilted toward the origin, indicating the value of the portfolio is lower relative to that in the case of joint monopoly. By comparing the values of the portfolio and the joint monopoly, we find that overinvestment caused by competition erodes firms' values as documented in the existing patent race literature. Figure 8 provides level curves for the percentage value dissipation as a function of the two firms' costs-to-completion. The expected rent dissipation is measured as the percentage difference between the combined values of the two firms under joint monopoly and duopoly patent race. The graph shows that rent dissipation is greater than $2 \%$ only around the equal costto-completion line. In this region, it is not efficient from the perspective of joint monopoly for 
the firm with higher cost-to-completion to invest, but the firm nevertheless invests because it is afraid to lose the competition. The maximum amount of rent dissipation can be in excess of 35\%.

What Do We Learn from Over-investment and Value Dissipation? In venture capital industry, a venture capitalist can invest in several start-up firms. These start-ups are called portfolio firms for the venture capitalist. Venture capitalists typically have substantial control over portfolio firms. Therefore, venture capitalists are more like joint monopoly. This model implies that venture capitalists should encourage their portfolio firms to coordinate more. In addition, if a venture capitalist owns the leader, it is valuable for it to include the follower into its portfolio. In doing so, the venture capitalist can not only potentially improve efficiency by reducing over-investment and value dissipation, but also earn a good hedge plan since the returns of the leader and the follower are negatively correlated as we will detail in the next subsection.

\section{B. Higher CAPM Beta, Higher Return Volatility and More Negative Correlation between the Returns of the Two Firms.}

Summary of the results in this sub-section:

1). Firms involved in a patent race have a higher CAPM beta, a higher return volatility and more negative return correlation relative to the joint monopoly when both firms invest in the patent race.

2). A firm's beta is a complicated non-linear function of its cost-to-completion or firm value. When a firm is close to victory, its beta is close to the patent beta. When a firm drops back further from victory but is still investing, its percentage exposure to patent-value-risk increases. When a firm continuously experiences setbacks and finally stops investing, its firm beta falls with its cost-to-completion.

3). The magnitude of the annualized return volatility of a start-up can be in excess of 100\%. This high level of return volatility for a venture-capital backed start-up is largely 
attributed to technological risks and is consistent with recent empirical findings documented by Cochrane [2004].

4). A start-up’s return volatility can be decomposed into three components corresponding the three sources of risk: systematic market demand risk, idiosyncratic technological risk of this firm and idiosyncratic technological risk of this firm's competitor. The proportion of each component changes with the firm's position in the race. When the firm is close to victory, its return volatility is mainly caused by market demand risk. When the firm is close to its competitor in the race, idiosyncratic technological risks of both firms account for the majority of its return volatility. When the firm is far behind and stops investing, the firm essentially stays away from the competition unless its competitor experiences setbacks. This firm's return volatility is mainly caused by its competitor's idiosyncratic technological risk in this situation.

5). When both firms invest in a patent race, a firm's CAPM beta and return volatility increase as a firm has technological setbacks or its competitor makes positive progresses.

6). The returns of the two firms evolved in the duopoly patent race are perfectly correlated by the common factor of patent value when neither firm invests and most negatively correlated when both invest.

In this paper, "return” refers to the return on firm value over interval $d t$, that is, the percentage change in firm value over interval $d t$, taking into account any dividend distributed over that interval. Firms' investments can be regarded as negative dividends. Since the firms are all-equity financed, the return on firm value equals the return on equity. Remember $P_{m}(t)$ is the value of a share in the market portfolio with dividends reinvested. Since $P_{m}(t)$ follows geometric Brownian motion, $\frac{d P_{m}}{P_{m}}=\left(r_{f}+\lambda_{m}\right) d t+\sigma_{m} d z_{m}$, the market return, 
$R_{m}(t)=\frac{d P_{m}}{P_{m}}=\left(r_{f}+\lambda_{m}\right) d t+\sigma_{m} d z_{m}$, is normally distributed with mean $\left(r_{f}+\lambda_{m}\right) d t$ and variance $\sigma_{m}^{2} d t$. Remember $\lambda_{m}$ is the market risk premium.

Proposition 1: In the continuous-time limit, the formula for a firm's CAPM beta, risk premium, return variance and return covariance with its competitor in a duopoly patent race with the three types of uncertainty discussed previously can be derived as follows.

1). A firm's CAPM beta is the product of the beta on the patent's cash flows (the patent beta) and the elasticity of the firm's value with respect to the patent value: $\beta_{i}=\beta\left(\frac{x}{F^{i}} F_{x}^{i}\right)=\beta \varepsilon, i=A, B$, where $\beta$ is the patent beta and $\varepsilon=\frac{x}{F^{i}} F_{x}^{i}$ is the elasticity. Accordingly, a firm's risk premium is the product of the risk premium on the patent's cash flows (the patent risk premium) and the elasticity of firm value with respect to the patent value, i.e., $\lambda_{i}=\beta_{i} \lambda_{m}=(\beta \varepsilon) \lambda_{m}=\left(\beta \lambda_{m}\right) \varepsilon=\lambda \varepsilon, i=A, B$, where $\lambda$ is the patent risk premium.

2). A firm's return volatility and return covariance with its competitor over interval $d t$ can be decomposed into market demand uncertainty, this firm's idiosyncratic technological uncertainty and the other firm’s idiosyncratic technological uncertainty:

$$
\begin{gathered}
\operatorname{Vol}\left(\frac{d F^{i}-I^{i} d t}{F^{i}}\right)=\sqrt{\left(\sigma x \frac{F_{x}^{i}}{F^{i}}\right)^{2}+I^{A} k^{A}\left(\theta^{A} \frac{F_{k^{A}}^{i}}{F^{i}}\right)^{2}+I^{B} k^{B}\left(\theta^{B} \frac{F_{k^{B}}^{i}}{F^{i}}\right)^{2}} \sqrt{d t}, i=A, B \\
\operatorname{Cov}\left(\frac{d F^{A}-I^{A} d t}{F^{A}}, \frac{d F^{B}-I^{B} d t}{F^{B}}\right)=\left[(\sigma x)^{2} \frac{F_{x}^{A}}{F^{A}} \frac{F_{x}^{B}}{F^{B}}+I^{A} k^{A}\left(\theta^{A}\right)^{2} \frac{F_{k^{A}}^{A}}{F^{A}} \frac{F_{k^{A}}^{B}}{F^{B}}+I^{B} k^{B}\left(\theta^{B}\right)^{2} \frac{F_{k^{B}}^{A}}{F^{A}} \frac{F_{k^{B}}^{B}}{F^{B}}\right] d t \text { (16). }
\end{gathered}
$$

Properties of CAPM Beta of Joint Monopoly. Figure 9 shows level curves for the joint monopoly's CAPM beta as a function of the two firms' costs-to-completion under the assumption that the beta on the patent's cash flows is 1.00 . The dotted-curves are the contour plot of firms' investment regions in the case of the joint monopoly. The level curves for the joint monopoly's beta have the same shape as the Leontief technology. When the efficient firm whose cost-to- 
completion is lower makes positive progresses (points move south or west), the joint monopoly's beta decreases. But the beta is always greater than one. Intuitively, this reflects the fact that the joint monopoly incorporates real options on the value of the patents. In this numerical example that the patent value $\mathrm{x}=100$, the beta of the joint monopoly is no higher than 1.4.

Properties of CAPM Beta of Duopoly Competition. Figures 10 and 11 show level curves for CAPM betas of firm A and the portfolio comprising firms $\mathrm{A}$ and $\mathrm{B}$ in the patent race. The layout for these figures is the same as that in Figure 9. The dotted-curves are the contour plot of firms’ investment regions. Figure 10 makes it clear that a firm's beta is a complicated non-linear function of its cost-to-completion. When firm A is close to victory, its beta is close to the patent beta. The beta is slightly above 1 due to the real option value. When firm A drops back from victory but still investing (the region above the lower dotted-curve), its CAPM beta increases. The beta can be in excess of 2. As firm A continues having bad luck and finally stops investing (the region blow the lower dotted-curve), its firm beta falls with its cost-to-completion. When firm A lags far behind, firm A's value is less sensitive to the patent value and more sensitive to its competitor's move. The risk associated with the move of the firm's competitor is its competitor's technological risk which is idiosyncratic. An interesting point to note is that when both firms invest, firm A's beta increases as firm A experiences setbacks (points move east) or firm B makes improvements (points move south). It is worthwhile to examine whether this is the case by studying the pharmaceutical industry or the software industry. The beta of the portfolio comprising both firms A and B, plotted in Figure 11, is calculated as the value weighted betas of the two firms. The range of the portfolio beta is between 1.1 and 1.8 in the region where both firms invest and intensely compete. The beta of the portfolio is higher in this region than that of the joint monopoly (shown in Figure 9), implying that competition drives up firms’ beta.

Properties of Annualized Return Volatility of Joint Monopoly. Figure 12 shows level curves for the joint monopoly's annualized return volatility. The layout of the axes is as in previous figures. The dotted-curves are the contour plot of the investment regions for the joint 
monopoly. The level curves for the joint monopoly’s annualized return volatility have the same shape as the Leontief technology. When the efficient firm whose cost-to-completion is lower makes positive progresses (points move south or west), the joint monopoly’s return volatility decreases. When either firm in the joint monopoly is close to the finishing line (firm A is close to the vertical axis or firm B is close to the horizontal axis), it is certain that the joint monopoly will complete the project and receive the patent. Therefore, the joint monopoly's return volatility is caused only by the market demand volatility $\sigma$, which is set to $\sigma=30 \%$. In general, the return volatility of the joint monopoly will not be higher than $40 \%$.

Properties of Annualized Return Volatility of Duopoly Competition. Figure 13 plots level curves for the annualized return volatility of firm A in the race. Figure 14 plots level curves for the fraction of firm A's return volatility caused by its idiosyncratic risk defined as the sum of the two firms' idiosyncratic technological risks (the sum of the second and third components of Eq. 15, the firm's return volatility formula). The dotted-curves are the contour plot of both firms' investment regions. Figures 13 and 14 show that in the region where both firms invest and intensely compete, firm A's return volatility and the fraction of idiosyncratic risk are increasing as firm A experiences setbacks (points move east) or firm B makes progress and moves towards south. Firm A's return volatility can be in excess of $100 \%$. This high level of return volatility is mainly attributed to idiosyncratic risk which accounts for $90 \%$ of the return volatility. This result is consistent with the empirical findings documented in Cochrane [2004]. Cochrane [2004] studies the risk and return of venture capital and finds that the arithmetic returns of venture capital, even after correction of selection bias, are very volatile, and the standard deviation is about $100 \%$. When firm A over invests relative to the joint monopoly (the region blow 45-degree line and above the lower dotted-curve), the over-investments push up firm A's return volatility and idiosyncratic risk as predicted by the return volatility formula Eq. 15. In a bull market, as the size of the market increases (points shift along a ray towards the origin), firms are more likely to invest and as a result they have higher return volatility and idiosyncratic risk. When firm A is 
close to victory, it is almost certain for it to win. Therefore, its idiosyncratic risk becomes tiny and firm A's return volatility is mainly caused by the market demand uncertainty. As shown in Figure 13, the return volatility is equal to the parameter value set for market demand volatility $\sigma=30 \%$ when firm A is close to vertical axis. When firm A is far behind in the race (the southeast corner), it stops investing until firm B experiences significant setbacks. Firm B's idiosyncratic technological risk accounts for about $90 \%$ of firm A's return volatility in that region.

Figure 15 provides level curves for the annualized return volatility of the portfolio comprising both firms A and B in the patent race. The portfolio return volatility is calculated as the volatility of the value weighted returns of firms A and B. As shown in the graph, high levels of return volatility are concentrated in the region where both firms invest and actively compete. The return volatility of the portfolio can be up to $100 \%$. One implication of the equilibrium worthy of further testing is that higher aggregate investments of competing firms are associated with higher return volatilities and idiosyncratic risks. A comparison of the annualized return volatility of the portfolio and that of the joint monopoly confirms this implication. Figure 16 provides level curves for the percentage difference between the return volatility of the portfolio and that of the joint monopoly. The graph shows that the return volatility of the portfolio is at least $30 \%$ higher than that of the joint monopoly when both firms invest. In this region, it is usually inefficient for the firm with higher cost-to-completion to invest, but the firm nevertheless invests because it is afraid losing the competition. This aggressive investment behavior pushes up return volatility. The maximum amount of the percentage difference can be $200 \%$.

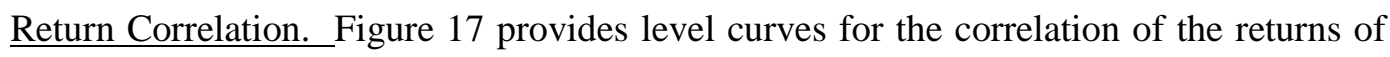
competing firms A and B, calculated from the firms' return volatility and return covariance. As in previous graphs, the dotted-curves are the contour plot of both firms' investment regions. In the region where neither firm invests, the values of the two firms are in principle perfectly correlated by the common factor of patent value. The correlation shown in the graph is 1 or very close to 1 due to discretized approximation. While resolution of uncertainty about the patent 
value makes the firms' returns positively correlated, resolution of uncertainty about the cost-tocompletion through investments introduces negative correlation. The return correlation can be 0.7 in the region where both firms invest. In a bull market, as the size of the market increases (thus points shift along a ray towards the origin), firms are more likely to invest such that the return correlation becomes more negative.

\section{COMPARATIVE-STATIC ANALYSIS}

In this section, we analyze briefly how market demand volatility, dividend yield, and technological volatility affect firms' investment decisions. ${ }^{16}$

\section{A. Market Demand Uncertainty Effect ( $\sigma$ Effect)}

In the base model, the market demand volatility parameter $\sigma$ is set to $\sigma=30 \%$. By increasing market demand volatility from $\sigma=30 \%$ to $\sigma=50 \%$, we find the following results.

1). On investment strategy: The effect of an increase in market demand uncertainty on investment strategies of a firm depends on the firm's position in the patent race. As market demand uncertainty increases, a firm delays making investments when it is either far ahead or behind in the race; it is eager to invest when the two firms are close in the race.

2). On value: As market demand uncertainty increases, a firm receives the real option premia of delay when it delays making investments.

3). Empirical implication: The relationship between investment and market demand uncertainty depends on a firm's position: it is negative when a firm is far ahead or behind, and it is positive when the firms are close in the race.

With market demand uncertainty, it is optimal for firms to delay making investments and wait for more information about the profitability of the new technology. This is why the existing literature on investment under uncertainty has concluded that the relationship between market demand uncertainty and investment is negative. But an increase in market demand uncertainty 
leads to a higher value of the option to delay as well as a higher up potential on patent value. In an environment with strategic interactions, any delay in investment may result in losing the higher patent value to the competitor. Balancing these pros and cons, a firm may find it optimal to delay making investments when it is either well ahead or far behind in the race, but is eager to invest when competition is intense. In sum, we find that the relationship between investment and market demand uncertainty depends on a firm's position in the race. ${ }^{17}$

\section{B. Dividend Yield Effect ( $\delta$ Effect)}

In the base model, the dividend yield $\delta$ is set to $\delta=3 \%$. By increasing dividend yield from $\delta=3 \%$ to $\delta=5 \%$, we find the following results.

1). On investment strategy: The effect of an increase in dividend yield on investment strategies of a firm depends again on the firm's position in the race. As dividend yield increases, a firm is eager to invest when it is ahead, but delays making investments when it is behind or close to the other firm.

Intuitively, the dividend yield $\delta$ represents the rate at which the present value of the patent decays through time as a result of no patent being granted; it represents the opportunity cost of deferring victory. One might expect that a firm always has incentives to invest when $\delta$

increases. This is the case when the project can be completed instantly, as in the model of McDonald and Siegel [1986]. When a project cannot be completed instantly, the result is not at all straight forward due to conflicting factors as explained in Majd and Pindyck [1986]. In that case, the winning firm can only obtain the patent upon completion. Holding the risk free rate, market risk premium and patent beta constant, the true growth rate $\mu$ and the risk-neutral growth rate $\mu^{*}$ decrease as dividend yield increases, which is evident from Eq. 9. So as dividend yield increases, the value of the patent at completion may be lower, giving firms an incentive to withhold investments. When a firm is close to victory, it is eager to invest more to save dividends. 
However, when a firm is close to or lags behind its competitor, it will withhold investments expecting that the patent value will be reduced.

\section{Technological Uncertainty Effect ( $\theta$ Effect)}

In the base model, the firms' technological volatility parameters $\theta^{A}$ and $\theta^{B}$ are set to $\theta^{A}=\theta^{B}=0.6$. Here we fix firm B's technological volatility parameter to $\theta^{B}=0.6$ and change firm A's technological volatility parameter to $\theta^{A}=0.9$ and $\theta^{A}=0.3$. We find the following results.

1). On investment strategy: An increase in the follower's technological uncertainty will encourage both firms to invest. An increase in the leader's technological uncertainty, however, will encourage the leader to invest but discourage the follower from investing. In other words, an increase in a firm's technological uncertainty encourages the firm to invest regardless of its position in the race. In contrast, the higher uncertainty encourages the firm's competitor to invest if the competitor is the leader but discourages if the competitor is the follower.

2). Empirical implication: The relationship between aggregate investments of two firms evolved in a patent race and one firm's idiosyncratic technological risk depends on this firm's position in the race. The aggregate investments are non-decreasing in the follower's idiosyncratic technological risk.

One of the nice features of the process of the expected cost-to-completion is that investments of a firm can result in technological improvements as well as technological setbacks. From the follower's perspective, an increase in its own technological uncertainty gives it a chance to catch up, so it invests aggressively. In contrast, an increase in technological uncertainty of the leader may result in the leader's setbacks, therefore, gives the follower an incentive to withhold investments pending more information on the leader's move in order to save investment costs. From the leader's perspective, an increase in its own technological uncertainty gives it an 
incentive to invest so that it can learn more information about investment costs and resolve its technological uncertainty. An increase in the follower's technological uncertainty may help the follower catch up, and therefore gives the leader an incentive to invest so as to maintain its leading position. In sum, the relationship between aggregate investments of both firms and a firm's idiosyncratic technological risk depends on the position of this firm in the race.

In all, the above sensitivity analysis implies the following:

Implication of the Comparative-Static Analysis: Firm position of a firm relative to that of its competitor in a race is an important control variable when we investigate a firm's investment behavior and other financial properties. We can use the degree of maturity or superiority of a firm's technology as proxy for its position in a patent race.

Regarding private start-ups, venture capitalists typically do stage-financing to monitor the start-ups. There are financing round A, round B, round C .... We could proxy a firm's position by using which financing round the firm is at. For public firms, it is harder to proxy firms' position. But, there should be some specific industrial characteristic, like the milestone ladder of a technology, which can be used as a criterion to rank technologies in each high-technology sector. For example, higher density indicates a more superior drive in the disk drive industry (as in Josh Lerner [1997]). If the objective is to reach a certain level of density, it is reasonable to assume that the firm with the higher level of density needs less money or less time to reach the targeted level. Another example is that there are standard stages of clinical trials in the biotechnology industry to indicate the degree of maturity of a technology. A firm at FDA approval stage could be reasonably assumed to spend less money or less time to receive an approval than a firm who is still at clinical trial stage I.

\section{CONCLUSION}

This paper develops a continuous-time real-options patent-race model to analyze financial properties of venture-capital backed start-up firms. The numerical analysis of the model 
can help entrepreneurs, venture capitalists, limited partners and other investors to make better decisions. The model can also serve as guidance for some future empirical work as venture capital databases become available.

This paper can also be extended in the following directions. This paper emphasizes the social loss resulting from a patent race. Further research can expand the scope of this paper by adding welfare analysis. Since we assume that the winner of the patent is a perfectly discriminating monopolist, a joint monopoly is socially optimal because it prevents value dissipating investments. If the winner of the patent is not a perfectly discriminating monopolist, then patent races can enhance social welfare by allowing consumers to access new technologies earlier. $^{18}$

Another expansion of this paper is to consider technological spillovers. While competition motivates a firm to invest, technological spillovers will motivate a firm to withhold investments so as to free ride on investment efforts of its rival. It is worthwhile to study a firm's investment behavior and other financial properties in a competitive environment with the presence of technological spillovers.

\section{APPENDIX A. The Derivation of the Bellman Equation of Firm A}

To evaluate the firms, we assume that the non-diversifiable risk in the patent value $x$ can be hedged by trading the market portfolio. With this assumption, we can price the firms without knowing investors' risk preference or the true growth rate $\mu$ of the patent value, as in Black-

Scholes. Construct a hedge portfolio: buy firm A, which is worth $F^{A}$, and sell short $n_{A}$ units of the market portfolio. The value of a share in the market portfolio with dividends reinvested is $P_{m}$. The hedging demand $n_{A}$ will be chosen so that the non-diversifiable risk of this portfolio is eliminated. The value of this portfolio is $Q=F^{A}-n_{A} P_{m}$. The total return on this portfolio over 
interval $d t$ is $d F^{A}-n_{A} d P_{m}-I^{A} d t$. By applying Ito's lemma and assuming that $d z^{A}$ and $d z^{B}$ are mutually independent, and are both independent of $d w$ :

$$
\begin{aligned}
& d F^{A}=\frac{\partial F^{A}}{\partial x} d x+\frac{\partial F^{A}}{\partial k^{A}} d k^{A}+\frac{\partial F^{A}}{\partial k^{B}} d k^{B}+\frac{1}{2} \frac{\partial^{2} F^{A}}{\partial x^{2}}(d x)^{2}+\frac{1}{2} \frac{\partial^{2} F^{A}}{\partial\left(k^{A}\right)^{2}}\left(d k^{A}\right)^{2}+\frac{1}{2} \frac{\partial^{2} F^{A}}{\partial\left(k^{B}\right)^{2}}\left(d k^{B}\right)^{2} \\
& =F_{x}^{A}(\mu x d t+\sigma x d w)+F_{k^{A}}^{A}\left[-I^{A} d t+\theta^{A}\left(I^{A} k^{A}\right)^{1 / 2} d z^{A}\right]+F_{k_{t}^{B}}^{A}\left[-I^{B} d t+\theta^{B}\left(I^{B} k^{B}\right)^{1 / 2} d z^{B}\right] \\
& +\frac{1}{2} F_{x x}^{A} \sigma^{2} x^{2} d t+\frac{1}{2} F_{k^{A} k^{A}}^{A} \theta^{A 2} I k^{A} d t+\frac{1}{2} F_{k^{B} k^{B}}^{A} \theta^{B 2} I^{B} k^{B} d t \\
& =\left(F_{x}^{A} \mu x-I^{A} F_{k^{A}}^{A}-I^{B} F_{k^{B}}^{A}+\frac{1}{2} F_{x x}^{A} \sigma^{2} x^{2}+\frac{1}{2} F_{k^{A} k^{A}}^{A} \theta^{A 2} I^{A} k^{A}+\frac{1}{2} F_{k^{B} k^{B}}^{A} \theta^{B 2} I^{B} k^{B}\right) d t \\
& +\sigma x F_{x}^{A} d w+\theta^{A}\left(I^{A} k^{A}\right)^{1 / 2} F_{k^{A}}^{A} d z^{A}+\theta^{B}\left(I^{B} k^{B}\right)^{1 / 2} F_{k^{B}}^{A} d z^{B}
\end{aligned}
$$

Note that we can decompose $d w$ into $d w=\beta \frac{\sigma_{m}}{\sigma} d z_{m}+\frac{\sigma_{I}}{\sigma} d z_{x}$. Hence, the total return on this portfolio over interval $d t$ is

$$
\begin{aligned}
& d F^{A}-n_{A} d P_{m}-I^{A} d t \\
= & \left(F_{x}^{A} \mu x-I^{A} F_{k^{A}}^{A}-I^{B} F_{k^{B}}^{A}+\frac{1}{2} F_{x x}^{A} \sigma^{2} x^{2}+\frac{1}{2} F_{k^{A} k^{A}}^{A} \theta^{A 2} I^{A} k^{A}+\frac{1}{2} F_{k^{B} k^{B}}^{A} \theta^{B 2} I^{B} k^{B}-n_{A}\left(r_{f}+\lambda_{m}\right) P_{m}-I^{A}\right) d t \\
+ & \left(\beta \sigma_{m} x F_{x}^{A}-n_{A} \sigma_{m} P_{m}\right) d z_{m}+\sigma_{I} x F_{x}^{A} d z_{x}+\theta^{A}\left(I^{A} k^{A}\right)^{1 / 2} F_{k^{A}}^{A} d z^{A}+\theta^{B}\left(I^{B} k^{B}\right)^{1 / 2} F_{k^{B}}^{A} d z^{B}
\end{aligned}
$$

To eliminate the non-diversifiable risk, that is the term with $d z_{m}$, we set the hedging demand as $n_{A}=\beta \frac{x F_{x}^{A}}{P_{m}}$. In doing so, the only risk associated with this portfolio is diversifiable, and therefore the expected rate of return on the portfolio must equal to the risk-free rate $r_{f}$. That is, $\underset{I^{A} \in\left[0, I_{m}\right]}{\operatorname{Max}}\left\{E\left(d F^{A}-n_{A} d P_{m}-I^{A} d t\right)\right\}=r_{f}\left(F^{A}-n_{A} P_{m}\right) d t$. Substitute $n_{A}=\beta \frac{x F_{x}^{A}}{P_{m}}$ into this equation, and re-grouping, the Bellman equation of firm A is:

$$
\underset{I^{A} \in\left[0, I_{\max }\right]}{\operatorname{Max}}\left\{\left(\frac{1}{2} \sigma^{2} x^{2} F_{x x}^{A}+\left(r_{f}-\delta\right) x F_{x}^{A}\right)+I^{A}\left(\frac{1}{2}\left(\theta^{A}\right)^{2} k^{A} F_{k^{A} k^{A}}^{A}-F_{k^{A}}^{A}-1\right)+I^{B}\left(\frac{1}{2}\left(\theta^{B}\right)^{2} k^{B} F_{k^{B} k^{B}}^{A}-F_{k^{B}}^{A}\right)+\left(-r_{f} F^{A}\right)\right\}=0
$$




\section{APPENDIX B. The Derivation of Firm Beta, Return Volatility and Return Covariance}

Beta of firm i:

From Ito’s lemma, the return of firm $\mathrm{i}, i=A, B$ :

$$
\begin{gathered}
\frac{d F^{i}-I^{i} d t}{F^{i}}=\left(\mu x \frac{F_{x}^{i}}{F^{i}}-I^{A} \frac{F_{k^{A}}^{i}}{F^{i}}-I^{B} \frac{F_{k^{B}}^{i}}{F^{i}}+\frac{1}{2} \sigma^{2} x^{2} \frac{F_{x x}^{i}}{F^{i}}+\frac{1}{2} \theta^{A 2} I^{A} k^{A} \frac{F_{k^{A} k^{A}}^{i}}{F^{i}}+\frac{1}{2} \theta^{B 2} I^{B} k^{B} \frac{F_{k^{B} k^{B}}^{i}}{F^{i}}-\frac{I^{i}}{F^{i}}\right) d t \\
+\sigma x \frac{F_{x}^{i}}{F^{i}} d w+\theta^{A}\left(I^{A} k^{A}\right)^{\frac{1}{2}} \frac{F_{k_{t}^{A}}^{i}}{F^{i}} d z^{A}+\theta^{B}\left(I^{B} k^{B}\right)^{\frac{1}{2}} \frac{F_{k^{B}}^{i}}{F^{i}} d z^{B} \\
\Rightarrow E\left(\frac{d F^{i}-I^{i} d t}{F^{i}}\right)=\left(\mu x \frac{F_{x}^{i}}{F^{i}}-I^{A} \frac{F_{k^{A}}^{i}}{F^{i}}-I^{B} \frac{F_{k^{B}}^{i}}{F^{i}}+\frac{1}{2} \sigma^{2} x^{2} \frac{F_{x x}^{i}}{F^{i}}+\frac{1}{2} \theta^{A 2} I^{A} k^{A} \frac{F_{k^{A} k^{A}}^{i}}{F^{i}}+\frac{1}{2} \theta^{B 2} I^{B} k^{B} \frac{F_{k^{B} k^{B}}^{i}}{F^{i}}-\frac{I^{i}}{F^{i}}\right) d t
\end{gathered}
$$

Since the patent value follows geometric Brownian motion $d x=\mu x d t+\sigma x d w$ and the dividend yield is $\delta$. The return on the patent is

$$
\begin{aligned}
& \frac{d x+\delta x d t}{x}=(\mu+\delta) d t+\sigma d w \\
& \Rightarrow E\left(\frac{d x+\delta x d t}{x}\right)=(\mu+\delta) d t
\end{aligned}
$$

And by assumption, the market return $R_{m}=\frac{d P_{m}}{P_{m}}=\left(r_{f}+\lambda_{m}\right) d t+\sigma_{m} d z_{m}$ is normally distributed with mean $\left(r_{f}+\lambda_{m}\right) d t$ and variance $\sigma_{m}^{2} d t$.

Therefore, the beta of the patent by CAPM is,

$$
\begin{gathered}
\beta=\frac{\operatorname{Cov}\left(\frac{d x+\delta x d t}{x}, R_{m}\right)}{\operatorname{Var}\left(R_{m}\right)}=\frac{E\left[\left(\frac{d x+\delta x d t}{x}-E\left(\frac{d x+\delta x d t}{x}\right)\right)\left(R_{m}-E\left(R_{m}\right)\right)\right]}{\sigma_{m}^{2} d t} \\
=\frac{E\left[\sigma d w \sigma_{m} d z_{m}\right]}{\sigma_{m}^{2} d t}
\end{gathered}
$$

Similarly, the beta of firm $\mathrm{i}, \mathrm{i}=\mathrm{A}$ and $\mathrm{B}$, by CAPM is : 


$$
\begin{aligned}
\beta_{i}=\frac{\operatorname{Cov}\left(\frac{d F^{i}-I^{i} d t}{F^{i}}, R_{m}\right)}{\operatorname{Var}\left(R_{m}\right)}=\frac{E\left[\left(\frac{d F^{i}-I^{i} d t}{F^{i}}-E\left(\frac{d F^{i}-I^{i} d t}{F^{i}}\right)\right)\left(R_{m}-E\left(R_{m}\right)\right)\right]}{\sigma_{m}^{2} d t} \\
=\frac{E\left[\sigma x \frac{F_{x}^{i}}{F^{i}} d w \sigma_{m} d z_{m}\right]}{\sigma_{m}^{2} d t}=\frac{E\left[\sigma d w \sigma_{m} d z_{m}\right]}{\sigma_{m}^{2} d t}\left(x \frac{F_{x}^{i}}{F^{i}}\right)=\beta \varepsilon
\end{aligned}
$$

where $\varepsilon=x \frac{F_{x}^{i}}{F^{i}}$ is the elasticity of firm i's value with respect to the patent value.

The return volatility of firm i over interval $d t, i=A, B$ :

$$
\begin{aligned}
\Rightarrow \operatorname{Vol}\left(\frac{d F^{A}-I^{A} d t}{F^{A}}\right) & =\sqrt{E\left[\left(\frac{d F^{A}-I^{A} d t}{F^{A}}-E\left(\frac{d F^{A}-I^{A} d t}{F^{A}}\right)\right)^{2}\right]} \\
& =\sqrt{\left(\sigma x \frac{F_{x}^{i}}{F^{i}}\right)^{2}+I^{A} k^{A}\left(\theta^{A} \frac{F_{k^{A}}^{i}}{F^{i}}\right)^{2}+I^{B} k^{B}\left(\theta^{B} \frac{F_{k^{B}}^{i}}{F^{i}}\right)^{2}} \sqrt{d t}, i=A, B
\end{aligned}
$$

The covariance of the two firms' returns over interval $d t$ :

$$
\begin{aligned}
\operatorname{Cov}\left(\frac{d F^{A}-I^{A} d t}{F^{A}}, \frac{d F^{B}-I^{B} d t}{F^{B}}\right) & =E\left[\left(\frac{d F^{A}-I^{A} d t}{F^{A}}-E\left(\frac{d F^{A}-I^{A} d t}{F^{A}}\right)\right)\left(\frac{d F^{B}-I^{B} d t}{F^{B}}-E\left(\frac{d F^{B}-I^{B} d t}{F^{B}}\right)\right)\right] \\
& =\left[(\sigma x)^{2} \frac{F_{x}^{A}}{F^{A}} \frac{F_{x}^{B}}{F^{B}}+I^{A} k^{A}\left(\theta^{A}\right)^{2} \frac{F_{k^{A}}^{A}}{F^{A}} \frac{F_{k^{A}}^{B}}{F^{B}}+I^{B} k^{B}\left(\theta^{B}\right)^{2} \frac{F_{k^{B}}^{A}}{F^{A}} \frac{F_{k^{B}}^{B}}{F^{B}}\right] d t
\end{aligned}
$$




\section{REFERENCES}

Abel, Andrew B., 1983, Optimal Investment under Uncertainty, American Economic Review, 73, 228-33.

1984, The Effects of Uncertainty on Investment and the Expected Long-Run Capital Stock, Journal of Economic Dynamics and Control, 7, 39-54.

1985, A Stochastic Model of Investment, Marginal Q and the Market Value of the Firm, International Economic Review, 26, 305-22.

Berk, J., R. C. Green and V. Naik, 2004, Valuation and Return Dynamics of New Ventures, The Review of Financial Studies, 17, 1-35.

Bertola, Giuseppe, 1988, Adjustment Costs and Dynamic Factor Demands: Investment and Employment Under Uncertainty, Ph.D. Dissertation (Ch. 2), MIT.

Brennan, M. J., and E. Schwartz, 1985, Evaluating Natural Resource investments, Journal of Business, 58, 135-157.

Childs, P. and Alexander Triantis, 1999, Dynamic R\&D Investment Policies, Management Science, 45, 1359-1377.

Cochrane, John, 2004, The Risk and Return of Venture Capital, Working Paper University of Chicago.

Cox, J. C., and S. A. Ross, 1976, The Valuation of Options for Alternative Stochastic Processes, Journal of Financial Economics 3, 145-166.

Craine, Roger, 1988, Risky Business: The Allocation of Capital, Journal of Monetary Economics, 23, 201-18.

Dasgupta, P. and J. Stiglitz, 1980, Uncertainty, Industrial Structure and the Speed of R\&D, Bell Journal of Economics, 11, 1-28.

Dixit, A., 1989, Entry and Exit Decisions under Uncertainty, Journal of Political Economy, 97, 620-638.

Dixit A. K. and R. S. Pindyck, 1994, Investment Under Uncertainty. Princeton, NJ: Princeton University Press.

Fudenberg, D., R. Gilbert, J. Stiglitz and J. Tirole, 1983, Preemption, Leapfrogging and Competition in Patent Races. European Economic Review 22, 3-31.

Garlappi, L., 2004, Risk Premia and Preemption in R\&D Ventures. Forthcoming in the Journal of Financial and Quantitative Analysis.

Grenadier, S. R., 1996, The Strategic Exercise of Options: Development Cascades and Overbuilding in Real Estate Markets, Journal of Finance, 51, 1653-1679. 

$\overrightarrow{95-130 .}$

1999, Information Revelation Through Option Exercise, Review of Financial Studies, 12, 2000, Equilibrium with Time-to-Build: A Real Options Approach, in M. Brennan and L. Trigeorgis (eds.), Project Flexibility, Agency, and Competition, Oxford University Press, Oxford. , 2000, Game Choices: The Intersection of Real Options and Game Theory. Risk Books. , 2002, Option Exercise Games: An Application to the Equilibrium Investment Strategy of Firms. Review of Financial Studies, 15, 691-721.

Grossman, G. M. and C. Shapiro, 1987, Dynamic R\&D Competition. The Economic Journal, 97, 372-387.

Hartman, Richard, 1972, The Effects of Price and Cost Uncertainty on Investment, Journal of Economic Theory, 5, 258-66.

Harris, C. and J. Vickers, 1985, Perfect Equilibrium in a Model of a Race. Review of Economic Studies, 52, 193-209.

Harris, C. and J. Vickers, 1987, Racing with Uncertainty, Review of Economic Studies, 54,1-21.

Judd, K., 1985, Closed-loop Equilibrium in a Model of a Race. Discussion Paper No. 647. Management Economics and Decision Science, Kellogg Graduate School of Management, Northwestern University.

Kester, W. C., 1984, Today's Options for Tomorrow's Growth, Harvard Business Review, MarchApril, pp. 153-160.

Kogan, Leonid, 2001, An Equilibrium Model of Irreversible Investment, Journal of Financial Economics, 62, 201-245.

Kulatilaka, N., and E. Perotti, 1998, Strategic Growth Options, Management Science, 44, 0211031.

Kyle, Albert S. and Rujing Meng, 2004, Strategic Acquisitions and Investments in a Duopoly Patent Race under Uncertainty. Duke University Working Paper.

Lambrecht, B., and W. R. Perraudin, 1999, Real Options and Preemption under Incomplete Information, Working paper, IFR, Birkbeck College, London.

Leahy, John V. and Toni M. Whited, 1996, The Effect of Uncertainty on Investment: Some Stylized Facts. Journal of Money, Credit and Banking, 28, 64-83.

Leslie, K. J., and M. P. Michaels, 1997, The Real Power of Real Options, McKinsey Quarterly, (3), 5-23.

Longstaff, F. and Eduardo Schwartz, 2001, Valuing American Options by Simulation: A Simple Least-Squares Approach. The Review of Financial Studies, 14, 113-147.

Loury, G., 1979, Market Structure and Innovation. Quarterly Journal of Economics 93, 395-410. 
Majd, S., and R. Pindyck, 1987, Time to Build, Option Value, and Investment Decisions, Journal of Financial Economics, 18, 7-28.

Maskin, E., and Tirole, J., 1988, A Theory of Dynamic Oligopoly I: Overview and Quantity Competition and A Theory of Dynamic Oligopoly II: Price Competition, Kinked Demand Curves, and Edgeworth Cycles. Econometrica 56: 549-599.

McDonald, R., and D. Siegel, 1986, The Value of Waiting to Invest, Quarterly Journal of Economics, 101(4), 707-727.

Merton, R. C., 1973, The Theory of Rational Option Pricing, Bell Journal of Economics and Management Science, 4(Spring), 141-183.

Miltersen, K. and Schwartz, E., 2004, R\&D Investments with Competitive Interactions. NBER Working Paper No. w10258.

Moscarini, G., and Francesco Squintani, 2004, Competitive Experimentation with Private Information, Working Paper, University of Rochester.

Novy-Marx, R., 2002, An Equilibrium Model of Investment Under Uncertainty, Working Paper UC Berkeley.

Pindyck, R. S., 1988, Irreversible Investment, Capacity Choice, and the Value of the Firm, American Economic Review, 79, 969-985. , 1993, Investments of Uncertain Cost, Journal of Financial Economics 34, 53-76.

Reinganum, J., 1981, Dynamic Games of Innovations, Journal of Economic Theory, 25, 21-41. , 1982, A Dynamic Game of R and D: Patent Protection and Competitive Behavior Econometrica, 50, 671-688.

Schwartz, E. and M. S. Moon, 2000, Evaluating Research and Development Investments, in M. Brennan and L. Trigeorgis (eds.), Project Flexibility, Agency, and Competition, Oxford University Press, Oxford. , 2002, Patents and R\&D as Real Options, Working Paper, UCLA.

Smets, F. R., 1993, “Essays on Foreign Direct Investment,” unpublished dissertation, Yale University.

Press, William H., 1992, Numerical recipes in C: The Art of Scientific Computing, $2^{\text {nd }}$ edition. Cambridge University Press.

Tirole, Jean, 1988, The Theory of Industrial Organization. Cambridge, Massachusetts; London England: The MIT Press.

Triantis, A., and J. Hodder, 1990, Valuing Flexibility as a Complex Option, Journal of Finance, 45, 549-565. 
Trigeorgis, L., 1996, Real Options: Managerial Flexibility and Strategy in Resource Allocation. MIT Press, Cambridge, Mass.

Zeira, Joseph, February 1989, "Cost Uncertainty and the Rate of Investment," Hebrew University Working Paper No. 206. 
${ }^{1}$ The available databases are VentureXpert provided by Venture Economics and VentureSource provided by VentureOne.

${ }^{2}$ The results are robust to explicit finite difference method.

${ }^{3}$ Empirically, we can proxy joint monopoly by start-ups that work on the similar technology and controlled by the same venture capitalist and proxy competing firms in a patent race by start-ups that work on the similar technology and controlled by different venture capitalists.

4 “Options, Futures, \& Other Derivatives,” $4^{\text {th }}$ edition, by John Hull, p.g. 241.

${ }^{5}$ For an excellent review of this subject, please see the books by Dixit and Pindyck [1994] and Trigeorgis [1996].

${ }^{6}$ Schwartz and Moon [2000], Schwartz [2002] and Berk, Green and Naik [2004] consider the possibility that an exogenously catastrophic event may put an end to the firm.

${ }^{7}$ Grenadier [2000] does a good survey on this literature.

${ }^{8}$ The model and solution can be easily extended to an oligopolistic case involving a finite number of firms.

9 The general process of expected cost-to-completion in Pindyck [1993], allowing both technological uncertainty and input cost uncertainty, is $d k=-I d t+\theta k\left(\frac{I}{k}\right)^{\phi} d z, 0 \leq \phi \leq \frac{1}{2}$. The case of $\phi=0$ corresponds to input cost uncertainty. The version we use corresponds to $\phi=\frac{1}{2}$.

10 This can be justified by business news. For example, the 64-bit Intel super chip “Itanium” was initially to be released in 1997. However, a long series of delays pushed the chip's release date all the way into the first half of 2001.

${ }^{11}$ Kyle and Meng [2003] relax this assumption studying strategic acquisition and investment decisions, in which a firm with larger research bandwidth acquires a firm with smaller bandwidth.

${ }^{12}$ The Markovian strategies imply that firms cannot engage in history-dependent punishment strategies, which would support a more collusive equilibrium. It tends to support an equilibrium in which there is more rent dissipation than under alternative equilibrium concepts where firms behave more co-operatively. How much this issue of equilibrium concept matters is an issue for further research.

${ }^{13}$ The scenario that both firms have dominant strategies happens at more than 99\% of the decision nodes in the numerical implementation. 
14 Theoretically, we assume that firms get nothing if neither of them has won by time T. But, in the numerical implementation, we replace this assumption with a set of liquidation values designed to approximate in an ad hoc manner what might happen if the game were to continue. Specifically, we first calculate the expected profits of both firms under the assumption that the firm is a monopolist and there is no more volatility in either the patent value or the cost-to-completion. If one of the firms has a positive NPV and the other a negative NPV, then the positive NPV firm is assigned a liquidation value equal to its NPV and the negative NPV firm is assigned a liquidation value of zero. If both firms have a negative NPV value, both firms get zero. If both firms have a positive NPV value, we give each firm its NPV value multiplied by the ratio of the other firm's expected time-to-completion divided by the sum of both firms' expected time-to-completion, i.e., we make the "probability" of winning the NPV value inversely proportional to the expected time-to-completion. The ratio of the expected time-to-completion is the same as the ratio of the expected cost-to-completion because the two firms have the same maximum investment rate. We do not believe that this approximation has an economically significant effect on the results.

15 Based on the data source of PricewaterhouseCooper/Venture Economics/NVCA MoneyTree Survey, venture capital investment in United States companies decreased sharply after the bubble burst, from about 28.75 billion dollars in the first quarter of 2000 to about 4 billion dollars in the first quarter of 2003.

${ }^{16}$ Graphs of the comparative-static analysis are omitted. They are available upon request.

${ }^{17}$ Hartman [1972] and Abel [1983,1984,1985], etc., find a positive relationship between investment and market demand uncertainty by predicting that the marginal revenue product of capital is convex of market demand shock. Pindyck [1988], Bertola [1988], and Caballero and Pindyck [1996], etc., studying models with irreversible investments, instead find a negative relationship by predicting concave marginal revenue product of capital. Roger Craine [1988], emphasizing the covariance of a firm’s return with market return, also point to a negative relationship. Kulatilaka and Perotti [1998] and Kogan [2001] find the relationship ambiguous. The empirical work testing this relationship is limited. One exception is Leahy and Whited [1996]. It uses the volatility in stock market returns as a measure of uncertainty and favors the theory with irreversible investments that investment is negatively correlated with uncertainty through Tobin’s q. It does not control for firm position relative to competitors. Further empirical research is worth doing.

${ }^{18}$ Miltersen and Schwartz [2004], Moscarini and Squintani [2004] and Kyle and Meng [2004] are good references in this direction. 
Figure 1: Investment Strategies of Firms A and B in the Case of Joint Monopoly given the Patent Value $\mathrm{x}(\mathrm{t})=100$.

The horizontal axis is firm A's cost-to-completion. The vertical axis is B's cost-to-completion. The light gray (orange) area is where firm A invests and firm B does not. The dark (blue) area is where firm B invests and firm A does not. The un-shaded white area is where neither firm invests.

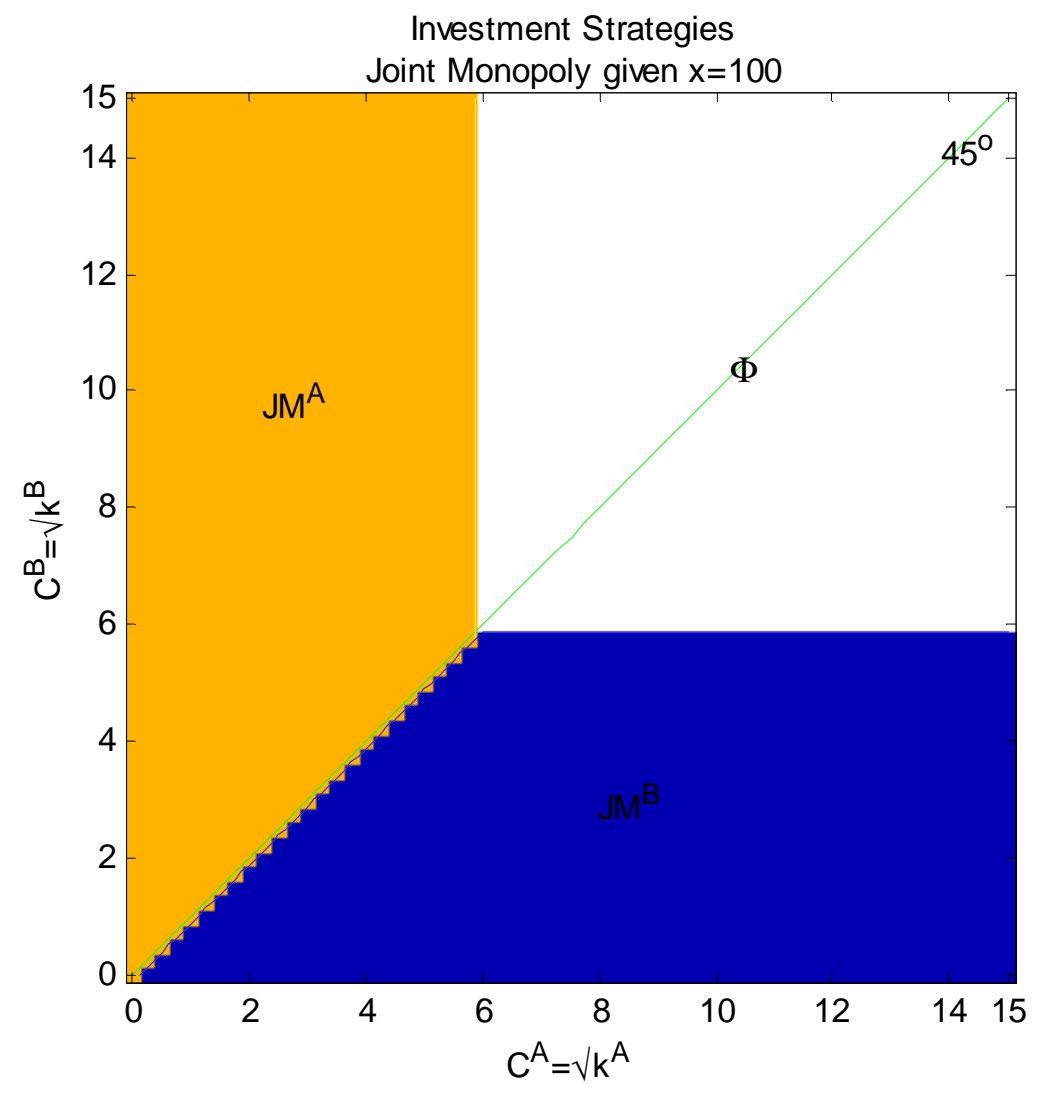


Figure 2: Investment Strategies of Firm A in the Patent Race given the Patent Value $\mathrm{x}(\mathrm{t})=100$.

The horizontal axis is firm A's cost-to-completion. The vertical axis is firm B's cost-to-completion. The light gray (yellow) area shows where firm A invests. The un-shaded white area shows where firm A mothballs.

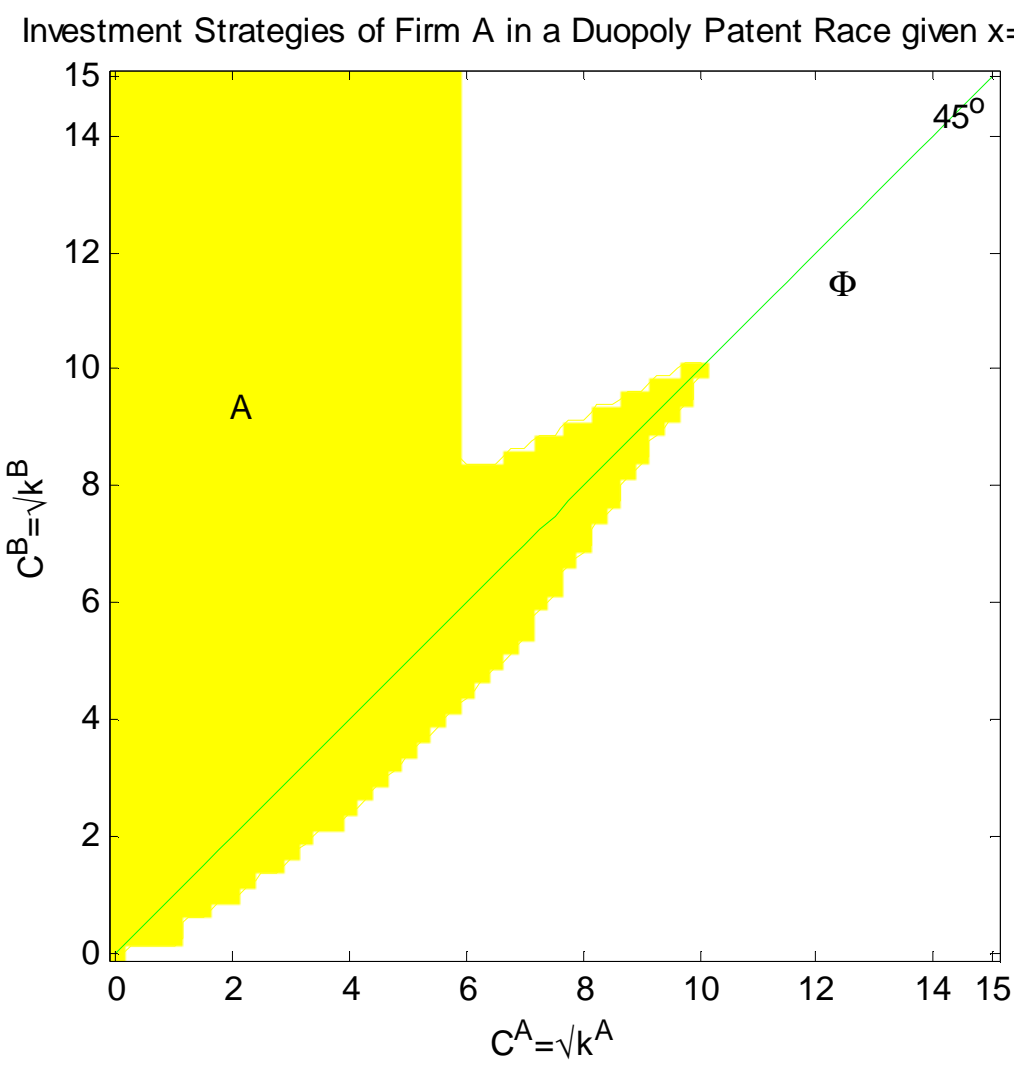


Figure 3: Investment Strategies of Firms A and B in the Patent Race given the Patent Value $\mathrm{x}(\mathrm{t})=100$.

The horizontal axis is firm A's cost-to-completion. The vertical axis is firm B's cost-to-completion. The light gray (yellow) area shows where firm A invests and firm B does not. The dark (blue) area shows where firm B invests and firm A does not. The medium gray (green) area shows where both firms invest. The un-shaded white area shows where neither firm invests.

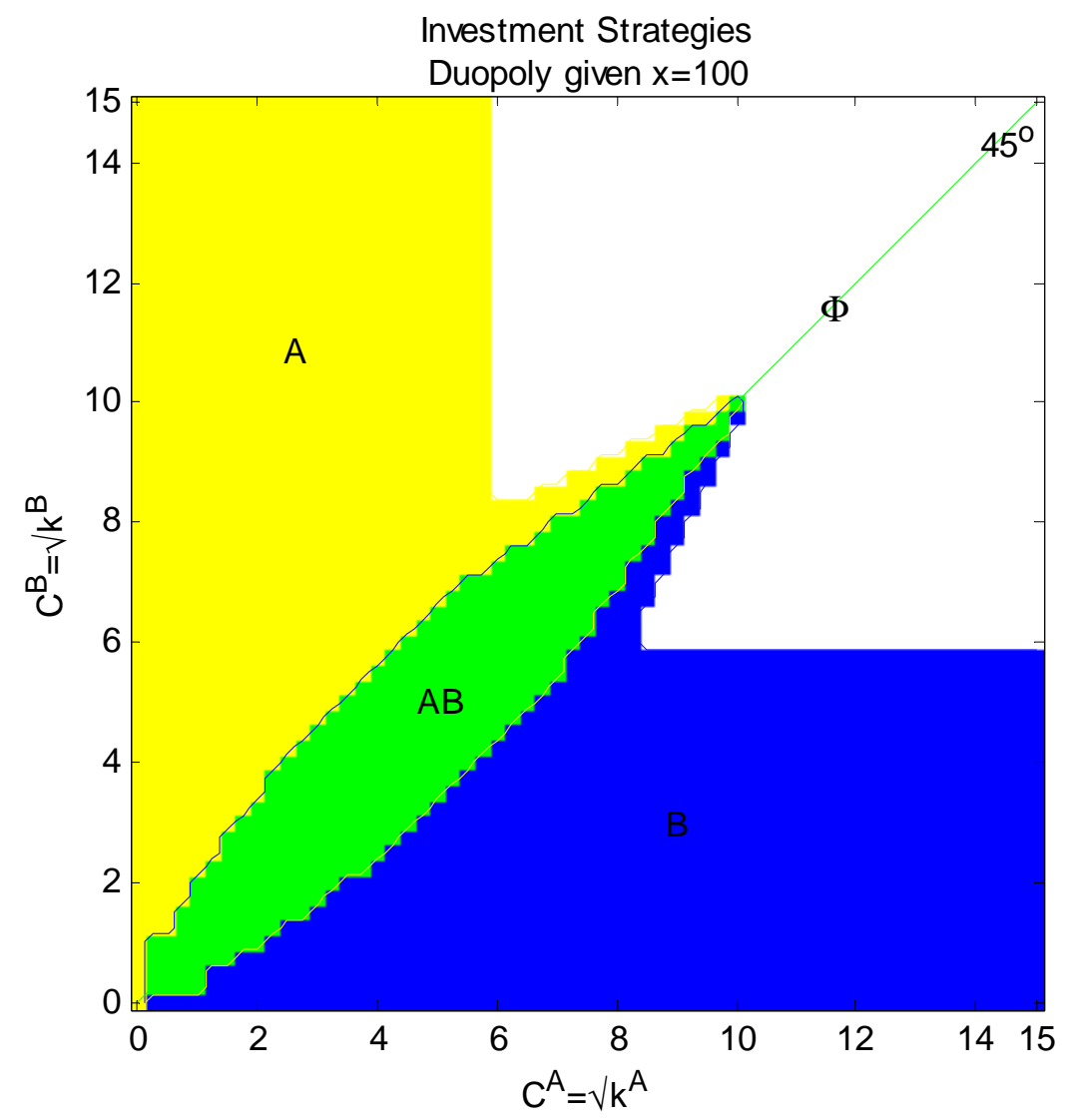


Figure 4: Investment Strategies of Firms A and B in the Patent Race given the Patent Value $\mathrm{x}(\mathrm{t})=151$.

The horizontal axis is firm A's cost-to-completion. The vertical axis is firm B's cost-to-completion. The light gray (yellow) area shows where firm A invests and firm B does not. The dark (blue) area shows where firm B invests and firm A does not. The medium gray (green) area shows where both firms invest. The un-shaded white area shows where neither firm invests.

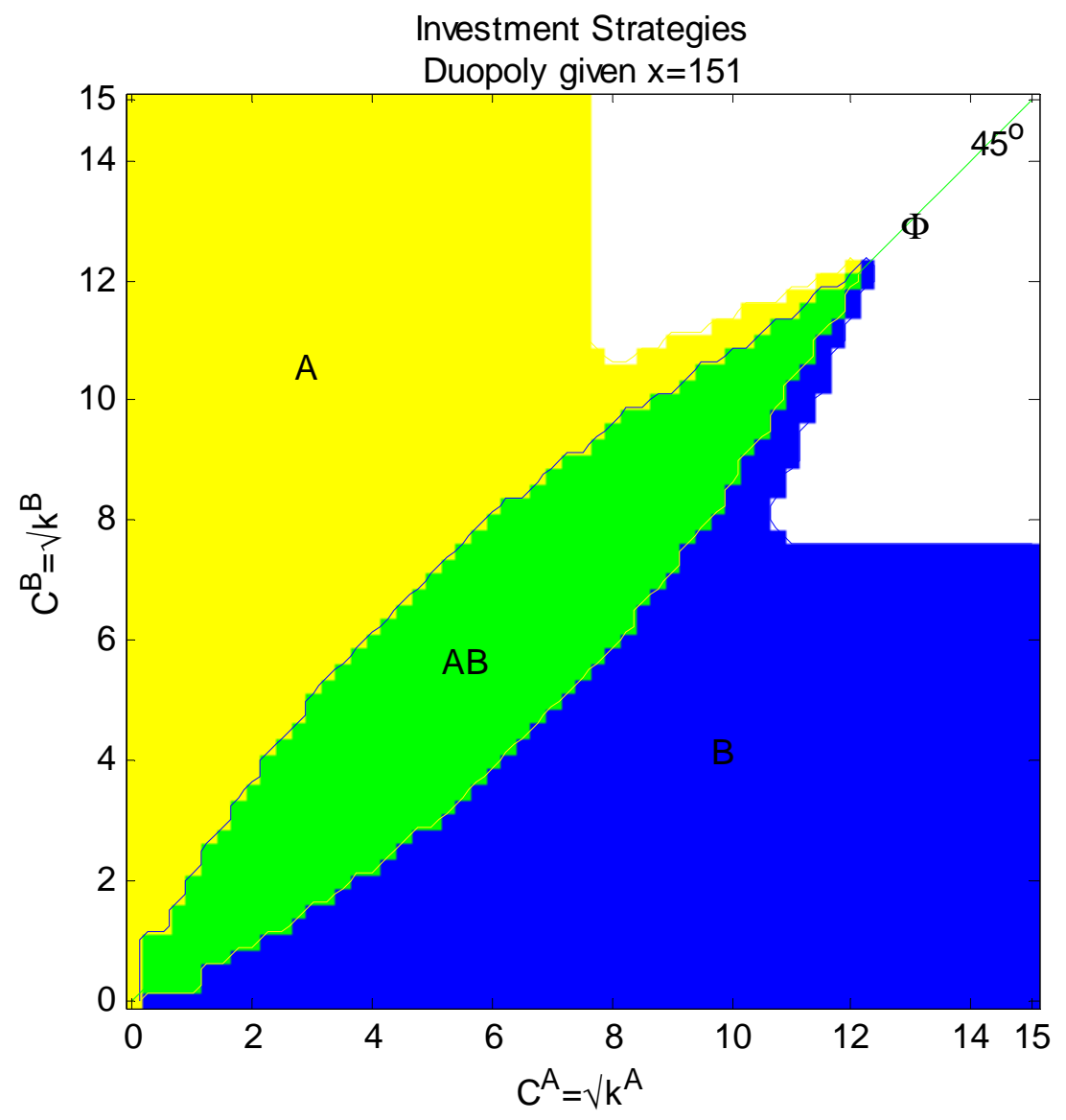


Figure 5: Iso-Value Lines for the Joint Monopoly given the Patent Value $x(t)=100$.

The horizontal axis is firm A's cost-to-completion. The vertical axis is firm B's cost-to-completion. The dotted-curves are the contour plot of the joint monopoly's investment regions. The intervals between the iso-value lines are 2 .

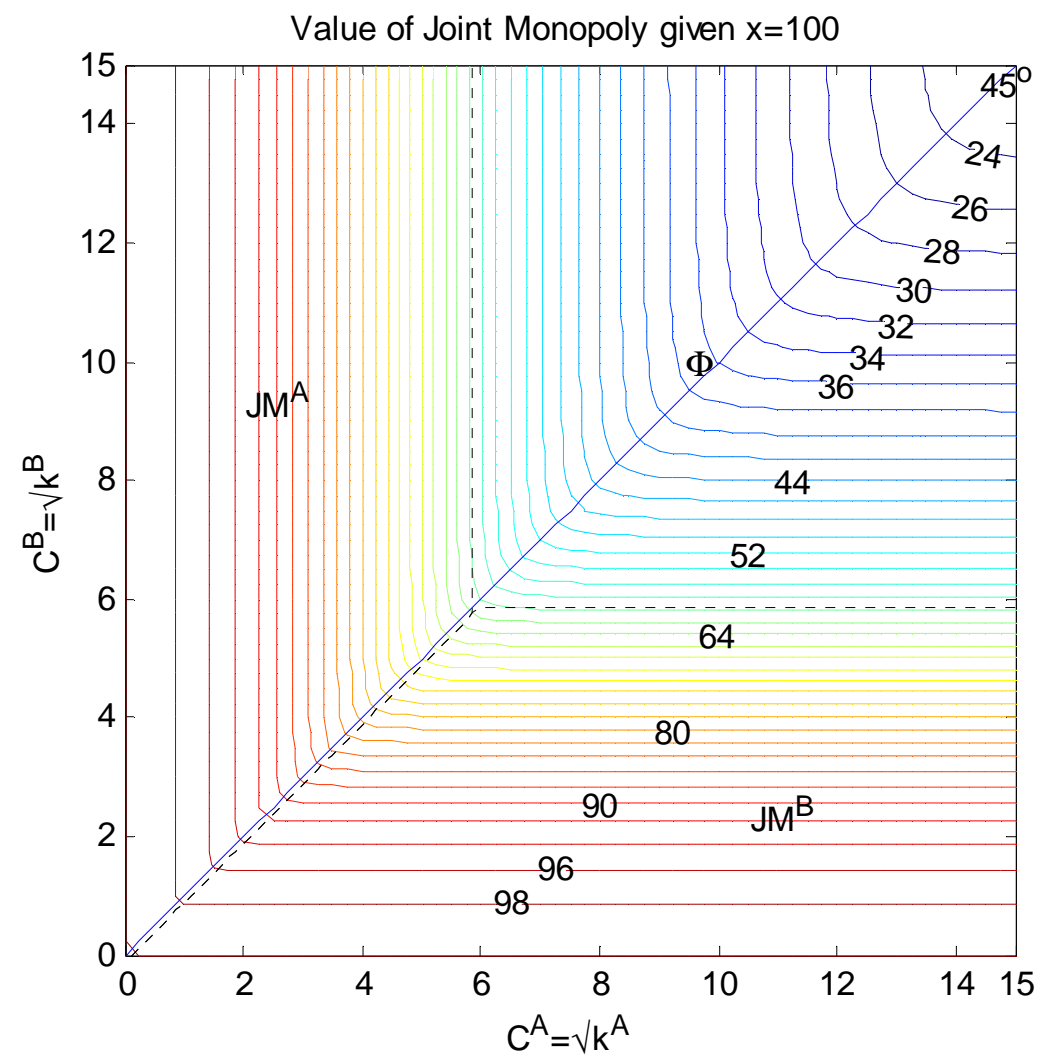


Figure 6: Iso-Value Lines for Firms A and B in the Patent Race given the Patent Value $\mathrm{x}(\mathrm{t})=100$.

The horizontal axis is firm A's cost-to-completion. The vertical axis is firm B's cost-to-completion. The dotted-curves are the contour plot of the firms' investment regions. The intervals between the iso-value lines represent factors of 2 in value.

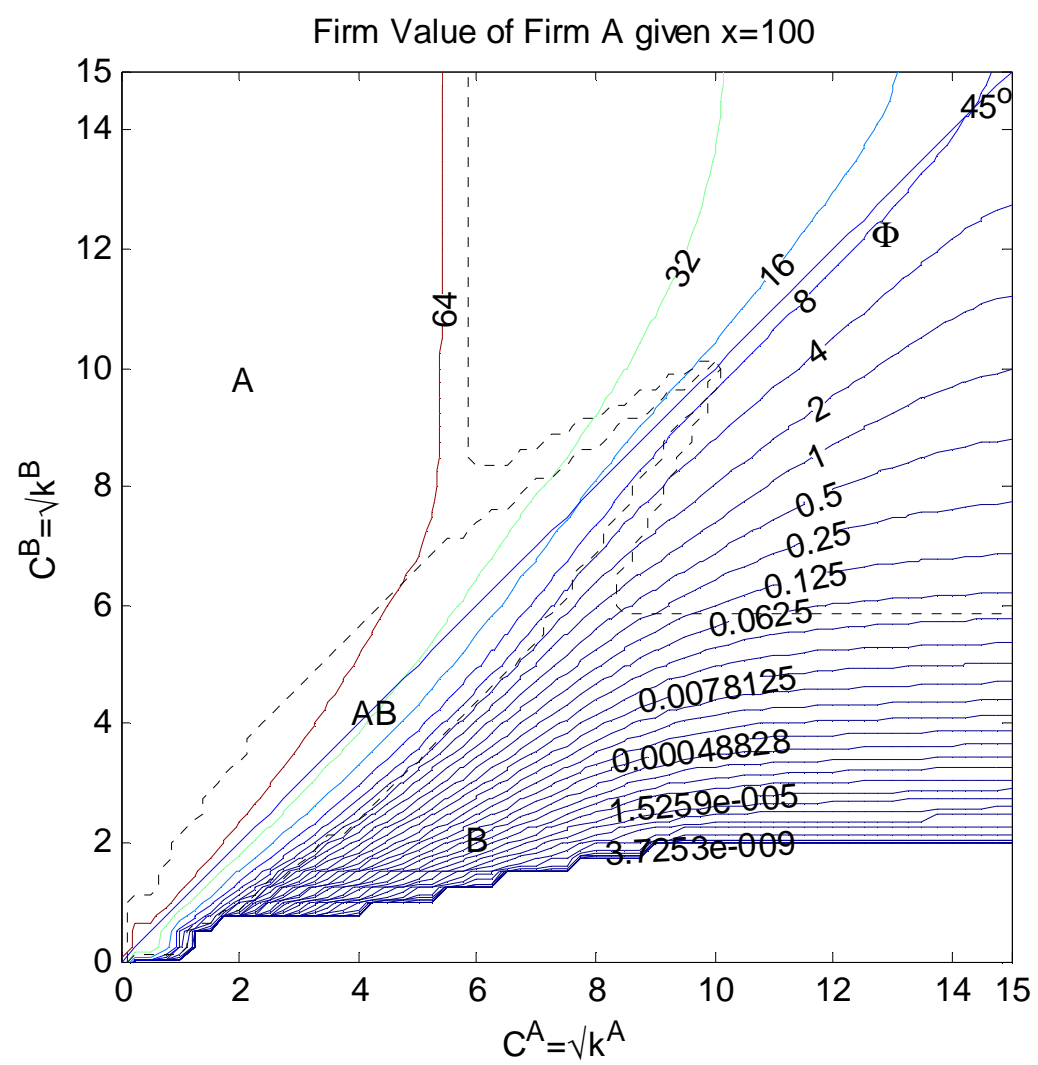


Figure 7: Iso-Value Lines for the Portfolio Comprising Firms A and B in the Patent Race given the Patent Value $x(t)=100$.

The horizontal axis is firm A's cost-to-completion. The vertical axis is firm B's cost-to-completion. The dotted-curves are the contour plot of the firms' investment regions. The intervals between the iso-value lines are 2.

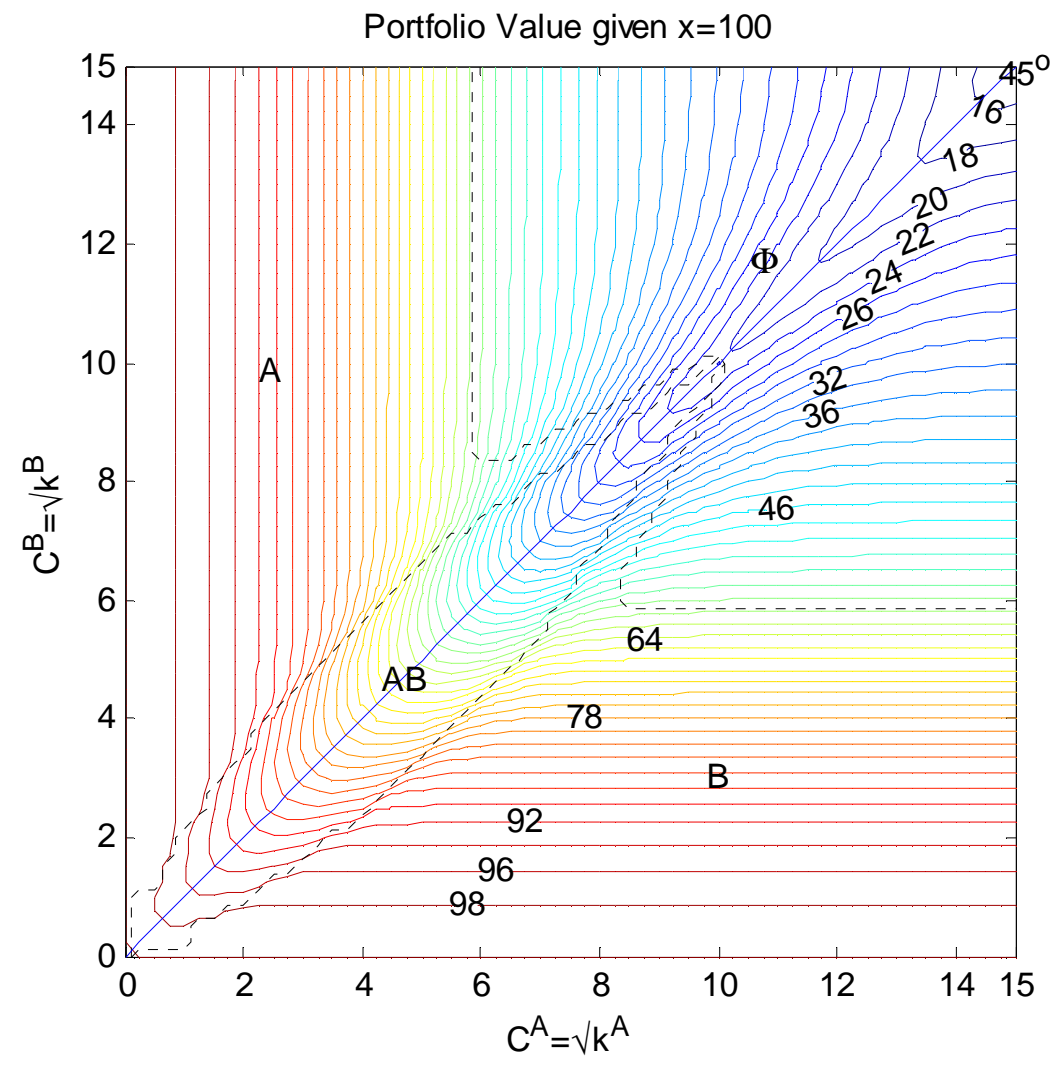


Figure 8: Level Curves for the Percentage Value Dissipation given the Patent Value $\mathrm{x}(\mathrm{t})=100$.

Expected rent dissipation is measured as the percentage difference between the combined values of the two firms under the joint monopoly and the duopoly patent race.

The horizontal axis is firm A's cost-to-completion. The vertical axis is firm B's cost-to-completion. The dotted-curves are the contour plot of firms' investment regions.

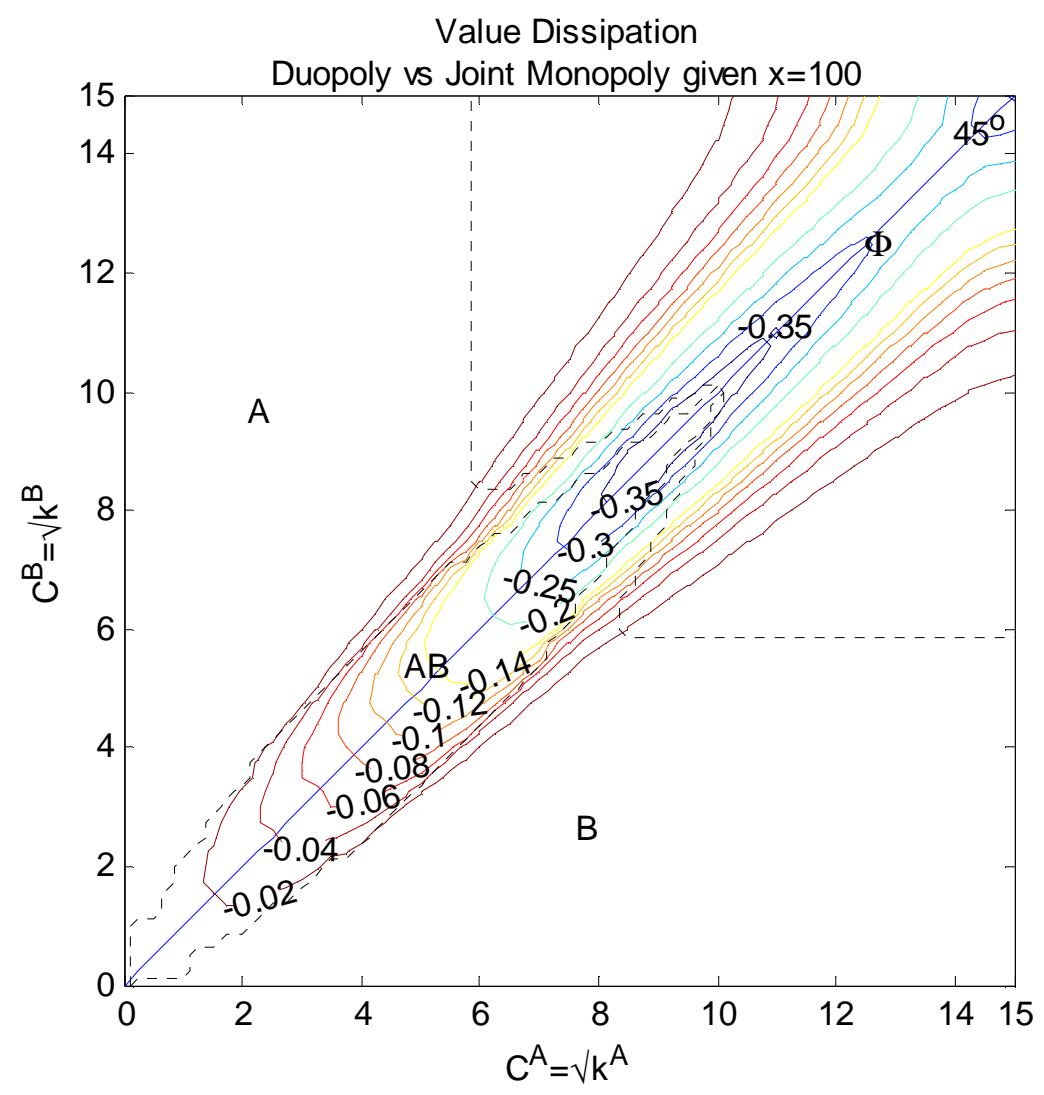


Figure 9: Level Curves for CAPM Beta of the Joint Monopoly given the Patent Value $\mathrm{x}(\mathrm{t})=100$.

The horizontal axis is firm A's cost-to-completion. The vertical axis is firm B's cost-to-completion. The dotted-curves are the contour plot of the joint monopoly's investment regions.

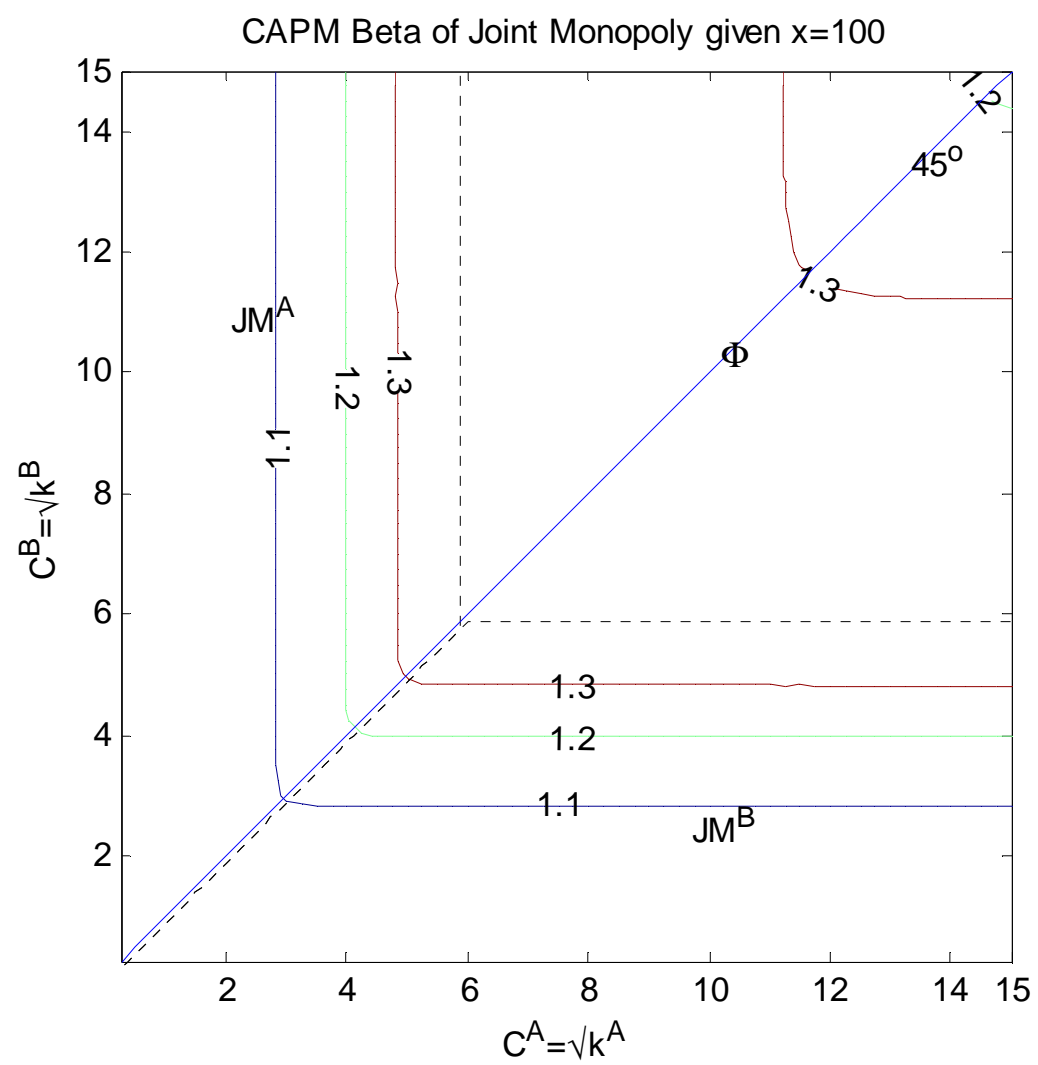


Figure 10: Level Curves for CAPM Beta of Firm A in the Patent Race given the Patent Value $\mathrm{x}(\mathrm{t})=100$.

The horizontal axis is firm A's cost-to-completion. The vertical axis is firm B's cost-to-completion. The dotted-curves are the contour plot of the firms' investment regions.

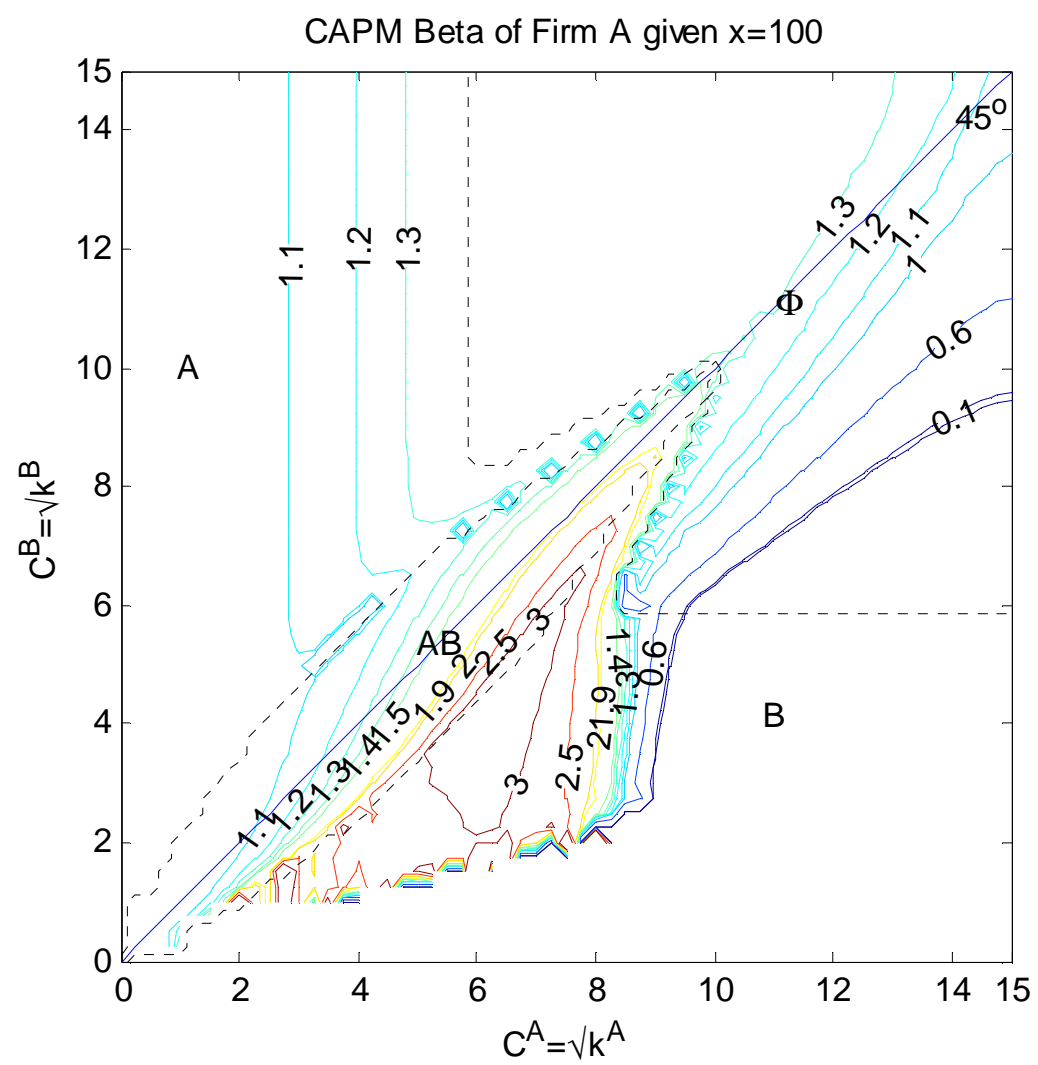


Figure 11: Level Curves for CAPM Beta of the Portfolio Comprising Firms A and B in the Patent Race given the Patent Value $\mathrm{x}(\mathrm{t})=100$.

The horizontal axis is firm A's cost-to-completion. The vertical axis is firm B's cost-to-completion. The dotted-curves are the contour plot of the firms' investment regions.

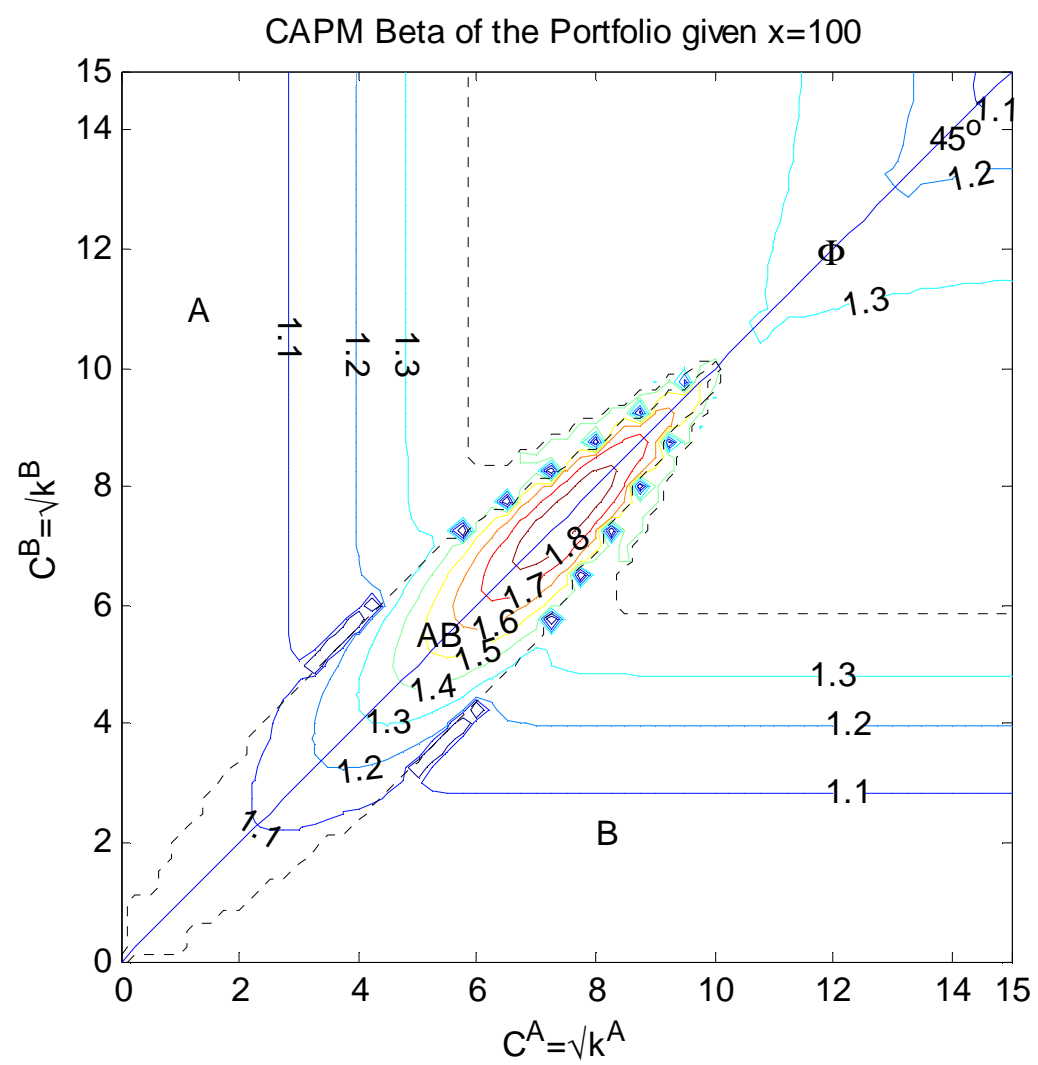


Figure 12: Level Curves for Annualized Return Volatility of the Joint Monopoly given the Patent Value $\mathrm{x}(\mathrm{t})=100$.

The horizontal axis is firm A's cost-to-completion. The vertical axis is firm B's cost-to-completion. The dotted-curves are the contour plot of the joint monopoly's investment regions.

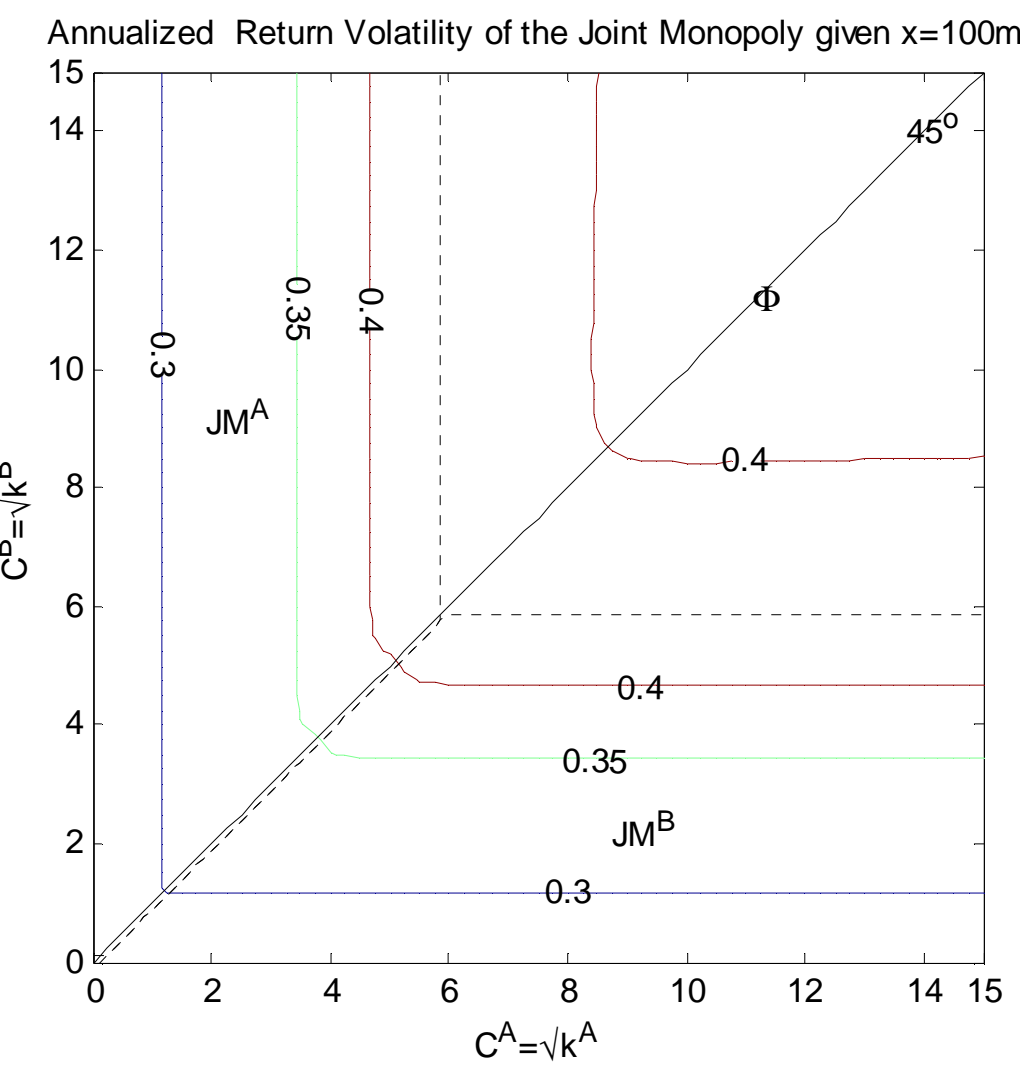


Figure 13: Level Curves for Annualized Return Volatility of Firm A in the Patent Race given the Patent Value $x(t)=100$.

The horizontal axis is firm A's cost-to-completion. The vertical axis is firm B's cost-to-completion. The dotted-curves are the contour plot of the firms' investment regions.

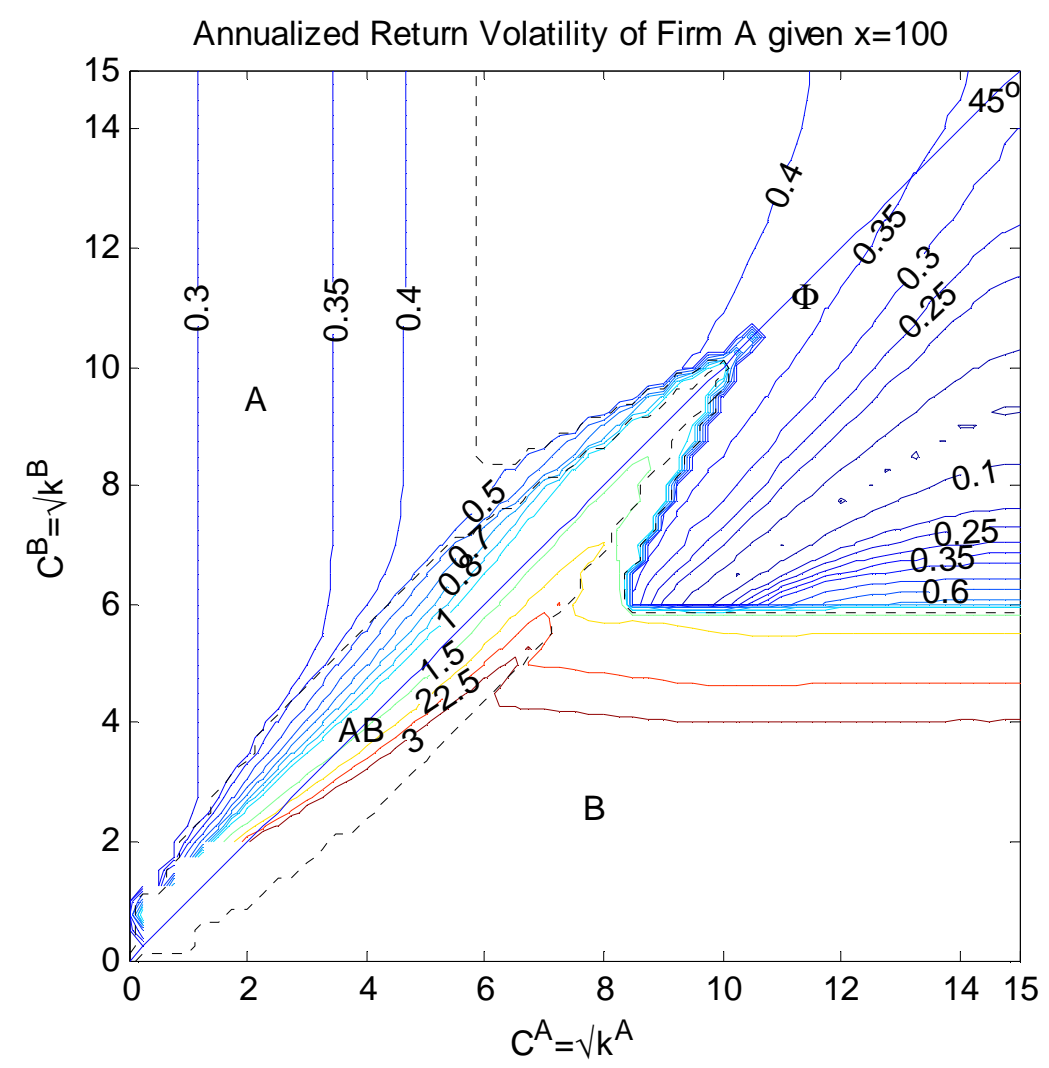


Figure 14: Level Curves for Fraction of Return Volatility of Firm A Caused by Its Idiosyncratic Risk given the Patent Value $\mathrm{x}(\mathrm{t})=100$.

The horizontal axis is firm A's cost-to-completion. The vertical axis is firm B's cost-to-completion. The dotted-curves are the contour plot of the firms' investment regions.

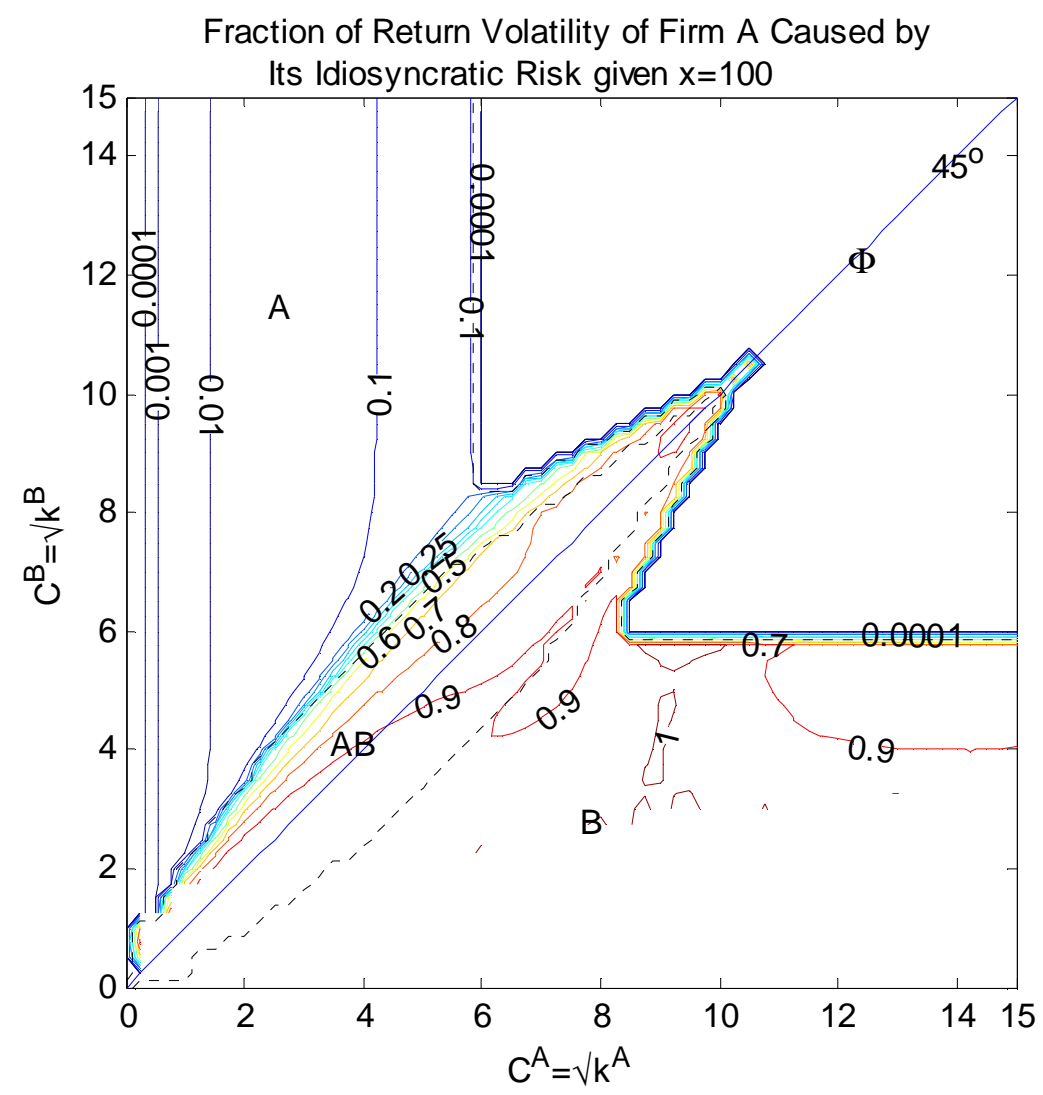


Figure 15: Level Curves for Annualized Return Volatility of the Portfolio Comprising Firms A and B in the patent Race given the Patent Value $x(t)=100$.

The horizontal axis is firm A's cost-to-completion. The vertical axis is firm B's cost-to-completion. The dotted-curves are the contour plot of the firms' investment regions.

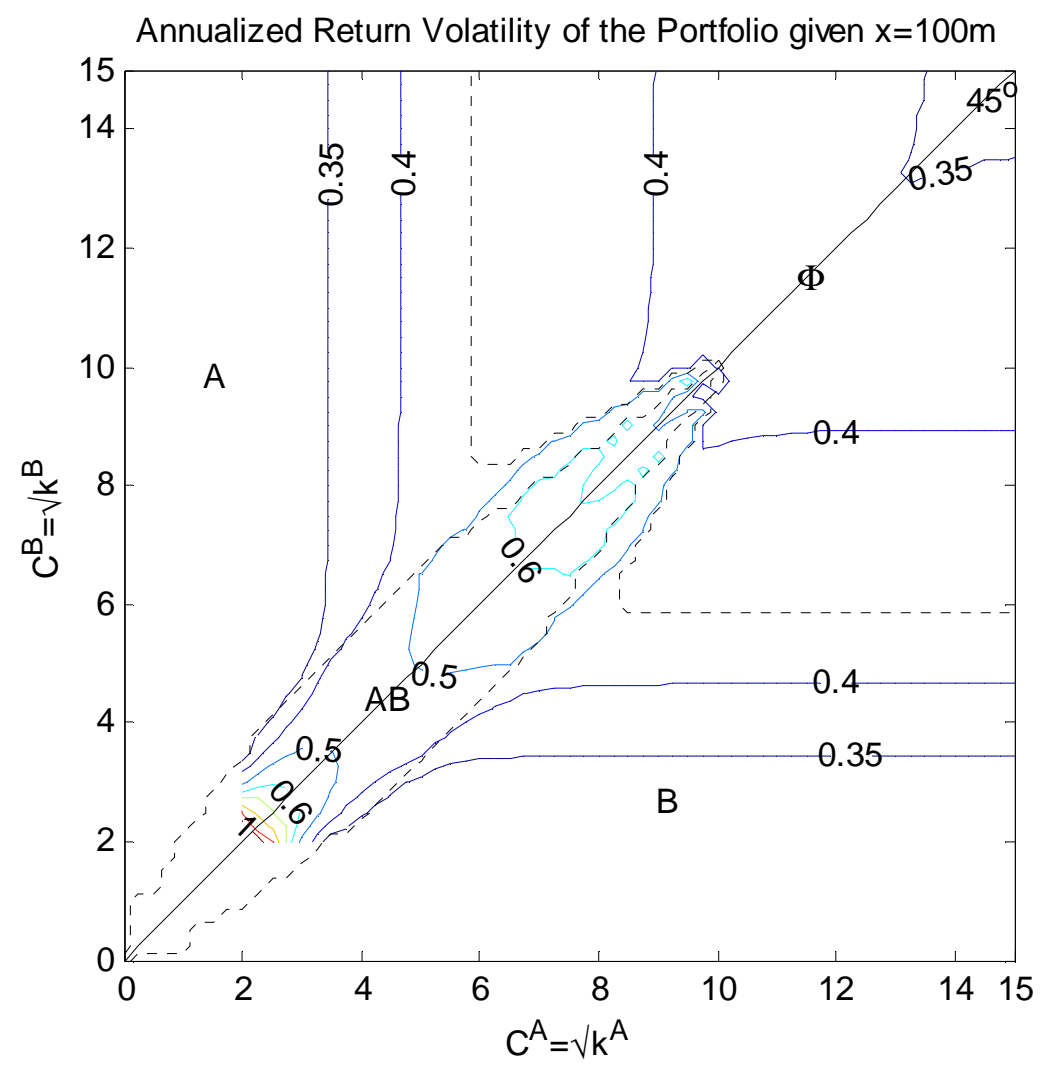


Figure 16: Level Curves for Percentage Difference of Annualized Return Volatility between the Portfolio Comprising Firms A and B in the patent Race and the Joint Monopoly given the Patent Value $x(t)=100$.

The horizontal axis is firm A's cost-to-completion. The vertical axis is firm B's cost-to-completion. The dotted-curves are the contour plot of the firms' investment regions.

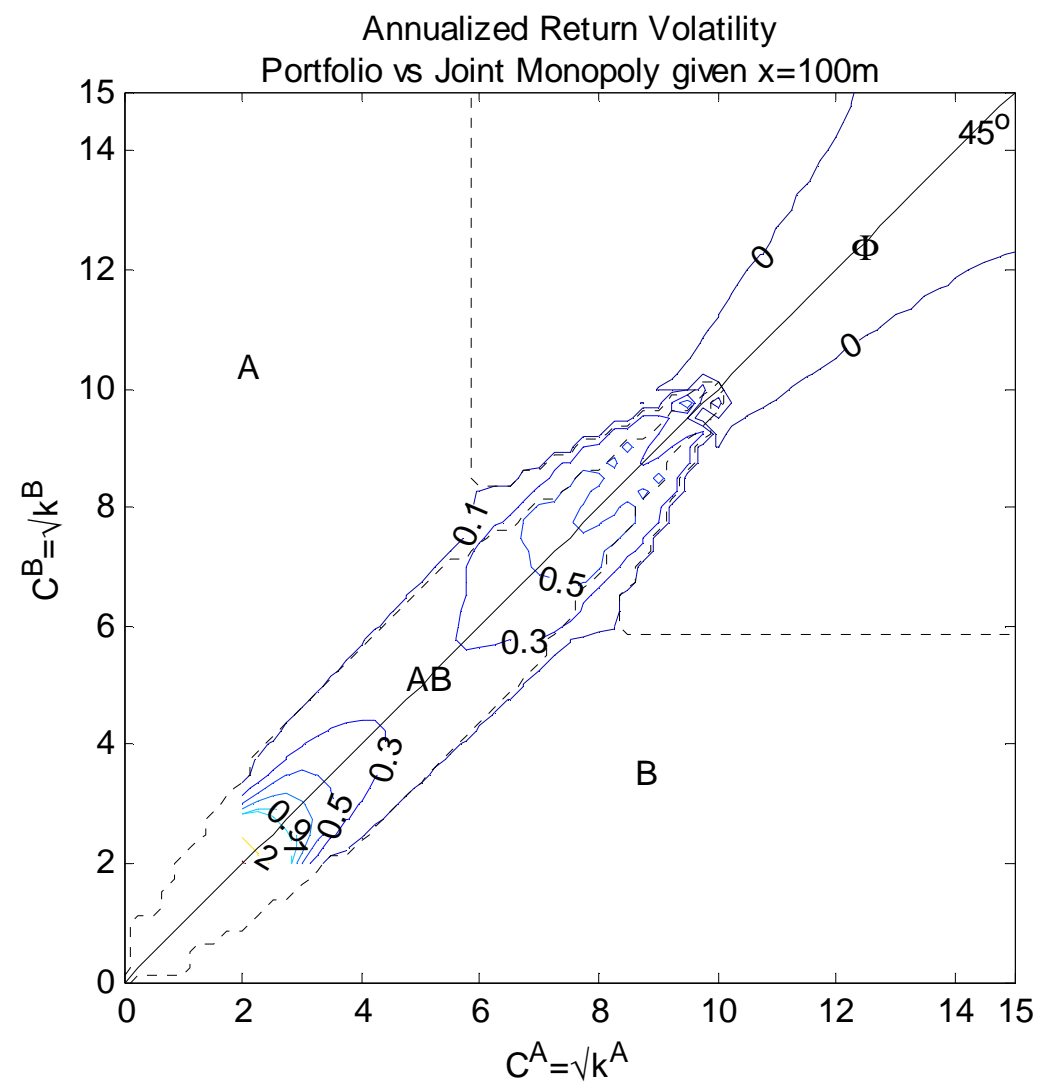


Figure 17: Level Curves for Return Correlation between the Firms A and B in the Patent Race given Patent Value $\mathrm{x}(\mathrm{t})=100$.

The horizontal axis is firm A's cost-to-completion. The vertical axis is firm B's cost-to-completion. The dotted-curves are the contour plot of the firms' investment regions.

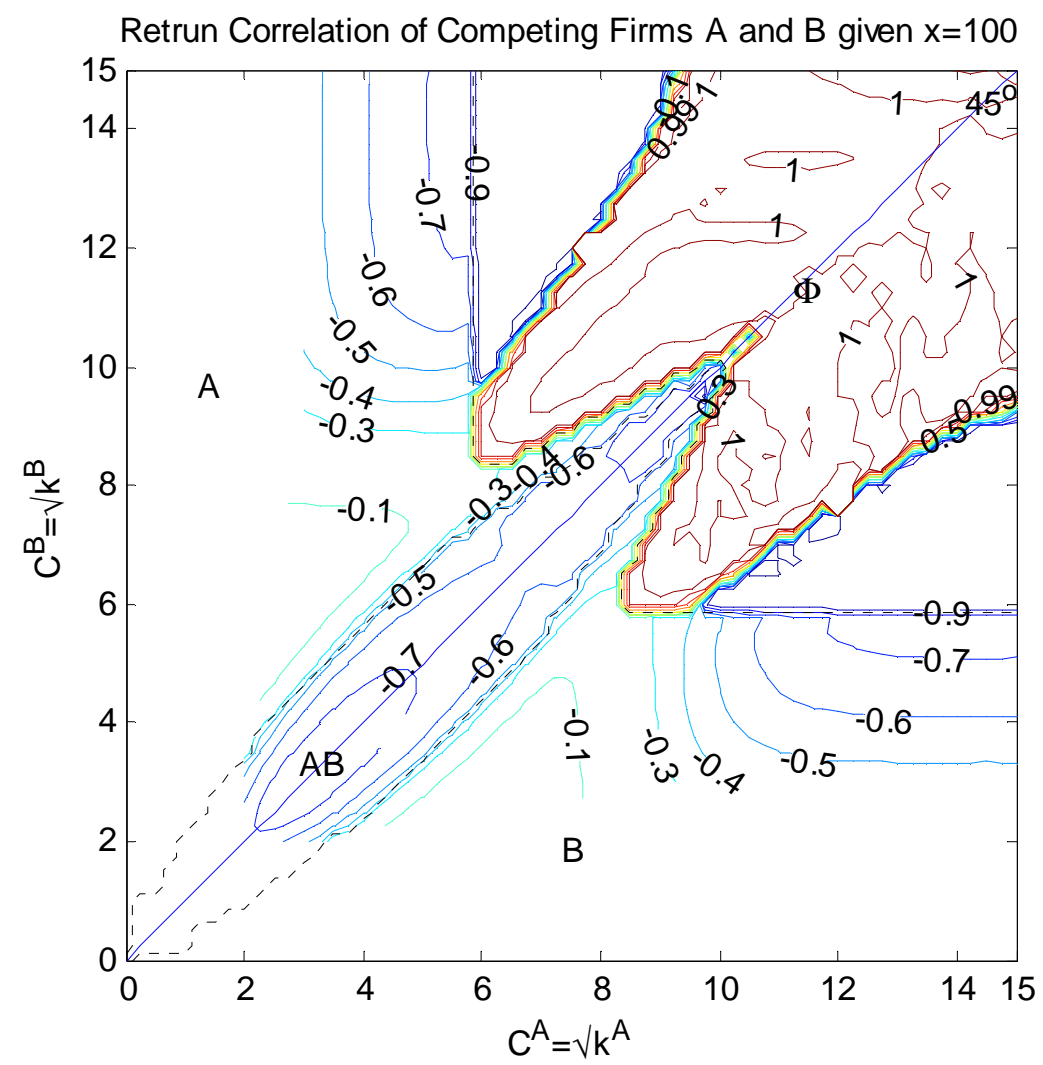

